\title{
Deciphering mechanisms of brain metastasis in melanoma - the gist of the matter
}

\author{
Torben Redmer ${ }^{1,2}$ D
}

\begin{abstract}
Metastasis to distant organs and particularly the brain still represents the most serious obstacle in melanoma therapies. Melanoma cells acquire a phenotype to metastasize to the brain and successfully grow there through complex mechanisms determined by microenvironmental than rather genetic cues. There do appear to be some prerequisites, including the presence of oncogenic BRAF or NRAS mutations and a loss of PTEN. Further mediators of the brain metastatic phenotype appear to be the high activation of the PI3K/AKT or STAT3 pathway or high levels of PLEKHA5 and MMP2 in metastatic cells. A yet undefined subset of brain metastases exhibit a high level of expression of CD271 that is associated with stemness, migration and survival. Hence, CD271 expression may determine specific properties of brain metastatic melanoma cells. Environmental cues - in particular those provided by brain parenchymal cells such as astrocytes - seem to help specifically guide melanoma cells that express CCR4 or CD271, potential "homing receptors". Upon entering the brain, these cells interact with brain parenchyma cells and are thereby reprogrammed to adopt a neurological phenotype. Several lines of evidence suggest that current therapies may have a negative effect by activating a program that drives tumor cells toward stemness and metastasis. Yet significant improvements have expanded the therapeutic options for treating brain metastases from melanoma, by combining potent BRAF inhibitors such as dabrafenib with checkpoint inhibitors or stereotactic surgery. Further progress toward developing new therapeutic strategies will require a more profound understanding of the mechanisms that underlie brain metastasis in melanoma.
\end{abstract}

Keywords: Melanoma, Brain metastasis, Microenvironment, Chemokines, CD271, PI3K/AKT signaling, Checkpoint inhibitors

\section{Background}

Metastases to the brain are observed in $10-40 \%$ of melanoma patients, although the number of metastatic lesions observed in brains post mortem is higher $(\sim 73-$ $90 \%)$, suggesting that most patients develop brain metastases during the course of the disease [1-3]. In 15-20\% of melanoma patients, the central nervous system (CNS) is the first site of relapse and is often accompanied by metastases in a second (41\%) and third organ (20\%) [4]. Currently the cumulative risk at 5 years for patients with melanoma to develop metastases in the CNS is about 7\% $[5,6]$. In addition, the time to development or detection

\footnotetext{
Correspondence: torben.redmer@charite.de

${ }^{1}$ Department of Dermatology, Venerology and Allergology, Charité Universitätsmedizin Berlin, Charitéplatz 1, D-10117 Berlin, Germany ${ }^{2}$ Department of Medical Biochemistry, University of Veterinary Medicine Vienna, Veterinärplatz 1, 1210 Vienna, Austria
}

of melanoma brain metastases ranges from $<1$ year to $>5$ years [6] with a median time of 2.5 years (30.5 months) [7]. Several risk factors have been identified, including the thickness (Breslow depth $>3 \mathrm{~mm}[8]$ ), ulceration [7] and the location of the primary melanoma [9].

Alongside clinical parameters, attempts to identify molecular markers that can predict the dissemination of melanoma cells to the brain have led to the identification of some promising candidates that might permit earlier diagnoses of the disease and generally better prognoses for patient outcomes. But the roles and functions of candidate markers such as cell surface proteins are not clearly understood: do they enhance the capacity of melanoma cells to metastasize to the brain, or are they induced by brain microenvironments and mediate cell survival and proliferation? Generally, a program that initially drives the initial spread of melanoma cells will

(c) The Author(s). 2018 Open Access This article is distributed under the terms of the Creative Commons Attribution 4.0 International License (http://creativecommons.org/licenses/by/4.0/), which permits unrestricted use, distribution, and 
not necessarily ensure the successful formation of brain macrometastases, as suggested by Fidler et al. [10, 11]. The high plasticity of melanoma cells, demonstrated by an unstable and fluctuating expression of cell surface markers [1-3], may enable cells to respond and adapt to prevailing environmental cues and be a prerequisite for the changes in their fundamental programming (Fig. 1a-b). This suggests that diverse melanoma cells may co-exist in stages with regard to the microenvironment that permit them to interconvert in response to stimuli such as growth factors, chemokines or cytokines [12] and epigenetic cues [13], reviewed in [14] (Fig. 1a). In the light of the diversity normally observed among melanoma cells, metastatic lesions in the brain might be the result of seeding by either a primary tumor or extracranial metastases. Cerebrotropic tumors, particularly desmoplastic neurotropic melanoma, have been reported to exhibit a high brain metastatic capacity [15]. Both scenarios, however, seem to be responsible for intra-tumor heterogeneity and the formation of metastases in the brain from melanoma [16]. A development of extracranial metastases may prime or select for melanoma cells with a higher brain metastatic propensity. This process is probably enhanced by therapeutic interventions and may explain the fact that patients who develop brain metastases during the course of the disease generally experience worse outcomes [17]. Another issue is the spatial and temporal distribution of brain metastases that might follow specific patterns of expression of growth factors. An investigative study of 115 brain metastases [18] revealed that the majority was located within the frontal lobe (43.5\%). Brain metastases were less frequently observed in the cerebellum (8.6\%) and rarely found in the hippocampus $(\sim 0-0.1 \%)$ (Fig. 1c) $[18,19]$. Whether the metastasis to a certain region within the brain is more likely than to other regions remains elusive.

In addition to the timing of the formation of brain metastases (BM), their number and location are of prognostic relevance. Patients with 1 to $3 \mathrm{BM}$ had a median OS of 5.92 months [17]. The outcome of patients with $>3$ BM located in the parenchyma was a median of 3.52 months, while metastases located in leptomeninges lead to a median of 1.22 months, respectively [17]. However, this data precede the currently available systemic therapies e.g. the combination of the BRAF inhibitor dabrafenib with trametinib, a very potent inhibitor of MEK1/2. The combination of both inhibitors in the COMBI-MB trial showed an intracranial response and improved OS (10.8 months) [20]. Multiple BM obtained from patients reveal strong inter-patient heterogeneity but a clear intratumor homogeneity [21] regarding the pattern of marker expression within tumors. This suggests a clonal evolution of multiple BM following the establishment of a founder clone or micrometastasis. Recently, Brastianos et al. demonstrated that primary tumors and brain metastases undergo divergent evolutionary paths [22]. Contrary, spatially and temporally separated metastases in single patients' brains corresponded to each other genetically, again suggesting that multiple BM arise from a single clonal source [22].

In principle, tumor cells frequently fail to complete all steps of the metastatic cascade, which leads to a low number of secondary lesions even in the presence of a high proportion of circulating tumor cells [11, 12]. Melanoma cells capable of brain colonization must develop mechanisms that mediate their survival as they circulate and actively transmigrate through the blood-brain-barrier (BBB). The BBB is formed by tightly connected endothelial cells that line cerebral microvessels. The barrier function relies on the presence of tight junction proteins including occludins, claudins and junctional adhesion molecules (JAM), which restrict the passive diffusion of solutes such as therapeutic drugs and small ions from the blood into the extracellular space of the CNS [23], reviewed in [24, 25]. Early studies in quails and chicks revealed that brain endothelial cells physically associate and interact with cells of the parenchyma, most significantly astrocytes, to induce the formation of the blood-brain barrier. This implies that the barrier is not intrinsically regulated by endothelial cells but depends on specific aspects of the brain microenvironment [26]. The perivascular endfeet of astrocytes particularly lie in close proximity to the walls of microvessels in the brain (Fig. 2a), facilitating astrocyte-endothelial signaling and inducing the formation of tighter tight junctions as well as other features of the BBB [24]. Several lines of evidence indicate that melanoma cells adhere to and disturb the interaction of brain endothelial cells through a disruption of tight and adherence junction proteins such as claudin 5 and ZO-1 in a way that facilitates transmigration [27]. In addition, proteolytic enzymes such as heparanase (HPSE1) and seprase (FAP; Fibroblast Activation Protein Alpha) are important for the capacity of metastatic cells to traverse the $\mathrm{BBB}$ and occupy the brain [27-29]. Once they have done so, micrometastases give rise to macrometastases through their proliferation along brain microvessels, as demonstrated by Kienast et al. [30], reviewed in [31]. The injection of cancer cells through a chronic cranial window permitted their real-time tracking in vivo using multiphoton laser-scanning microscopy [30]. This revealed that intracerebral seeding of brain macrometastases occurs either passively via the flow of cerebrospinal fluid through the meninges and ventricles or via active migration. The tracking of intracerebrally inoculated melanoma cells also revealed that melanoma cells actively migrate along leptomeningeal and brain parenchymal blood vessels [32].

Here I present recent findings on the mechanisms that drive brain metastasis in melanoma and discuss them in a broader context. 
a

SOX2
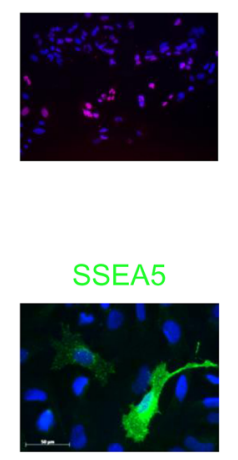

SSEA4

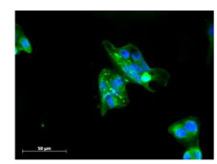

CD271/ CSPG4
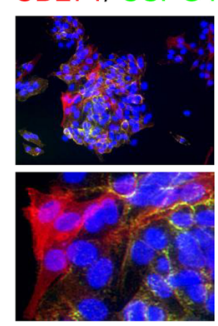

b

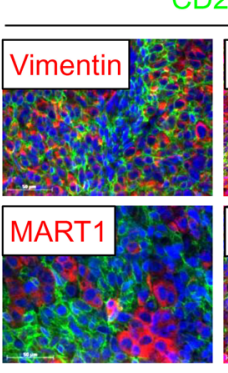

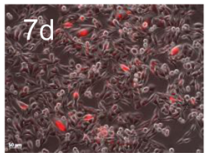
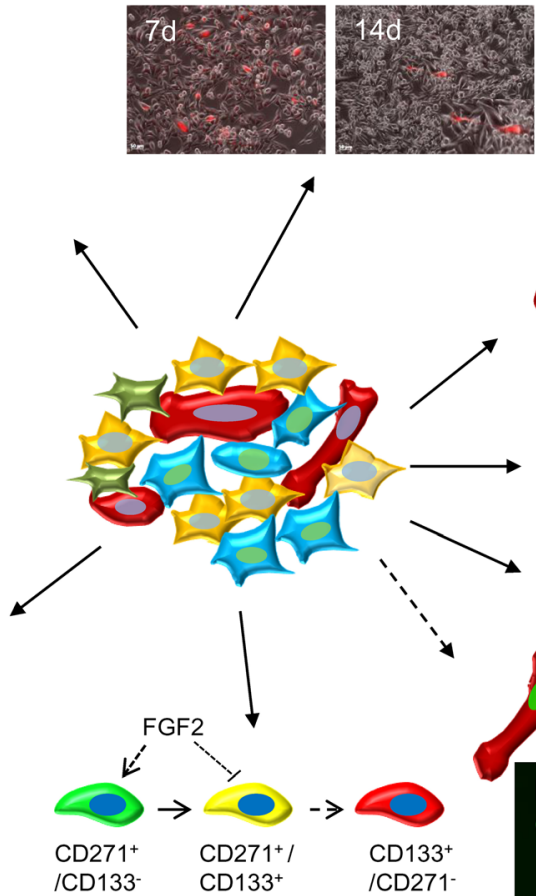

CD271/ CD133

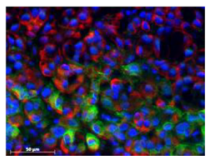

In vivo

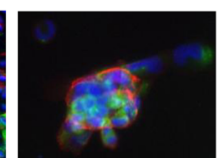

In vitro
CD271/ CD44

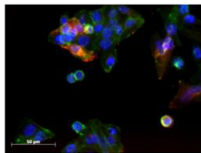

FGF13

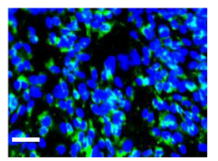

HMGA2

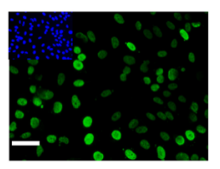

TRK(pan)/ CD271

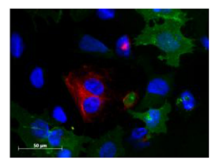

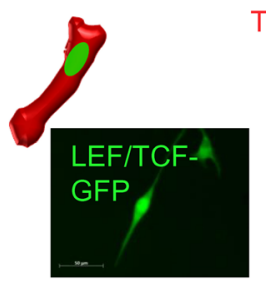

SOX10

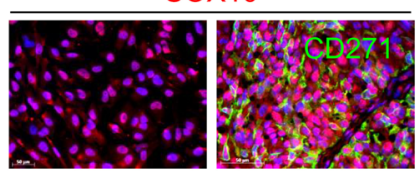

c
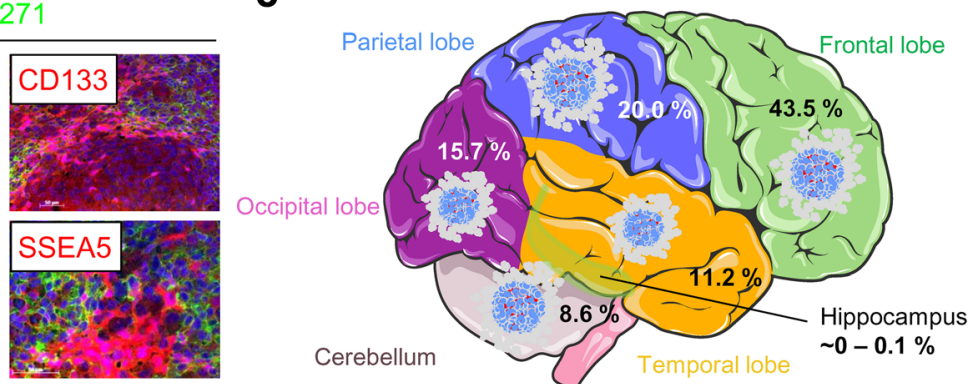

Fig. 1 Phenotypical heterogeneity of melanoma cells in vitro. a Immunofluorescence microscopy (IF) of melanoma cells revealed only a small number of cells positive for the stage-specific embryonic antigens (SSEA) 4 and 5; as well as slow-cycling cells which retain the lipophilic dye PKH26 (red). Cells with active WNT-signaling, driving expression of a LEF/TCF1-controlled GFP, or cells positive for either CD44 or tropomyosin-related kinases (TRKs) were infrequently observed as well. More frequently observed was the expression of CD271, HMGA2, FGF13, SOX10 (ubiquitous), SOX2, or CSPG4. Cultures of melanoma cells exhibiting co-existing, interconnected phenotypes as shown for CD271 and CD133 are rare. $\mathbf{b}$ Intratumor heterogeneity, shown by IF of tumors for CD271 (green) and either vimentin, CD133, MART1 or SSEA5 (all red). In (a) and (b), DAPI served as a nuclear dye. Scale bars indicate $50 \mu \mathrm{m}$. c Schematic representation of the regional distribution of melanoma brain metastases (BM), numbers represent the frequency of BM observed in 115 patients

\section{Current concepts of melanoma brain metastasis Oncogene-driven signaling pathways}

Oncogenic mutations of the serine-threonine kinase BRAF are found in 40-60\% of melanoma and $80 \%$ of melanocytic nevi (comprehensively reviewed in [33]), [34]. BRAF mutations are accompanied by amino acid (AA) exchanges of $\mathrm{V}$ (valine) to $\mathrm{E}$ (glutamic acid), $\mathrm{K}$ (lysine), D (aspartic acid) or R (arginine) at position 600 
a

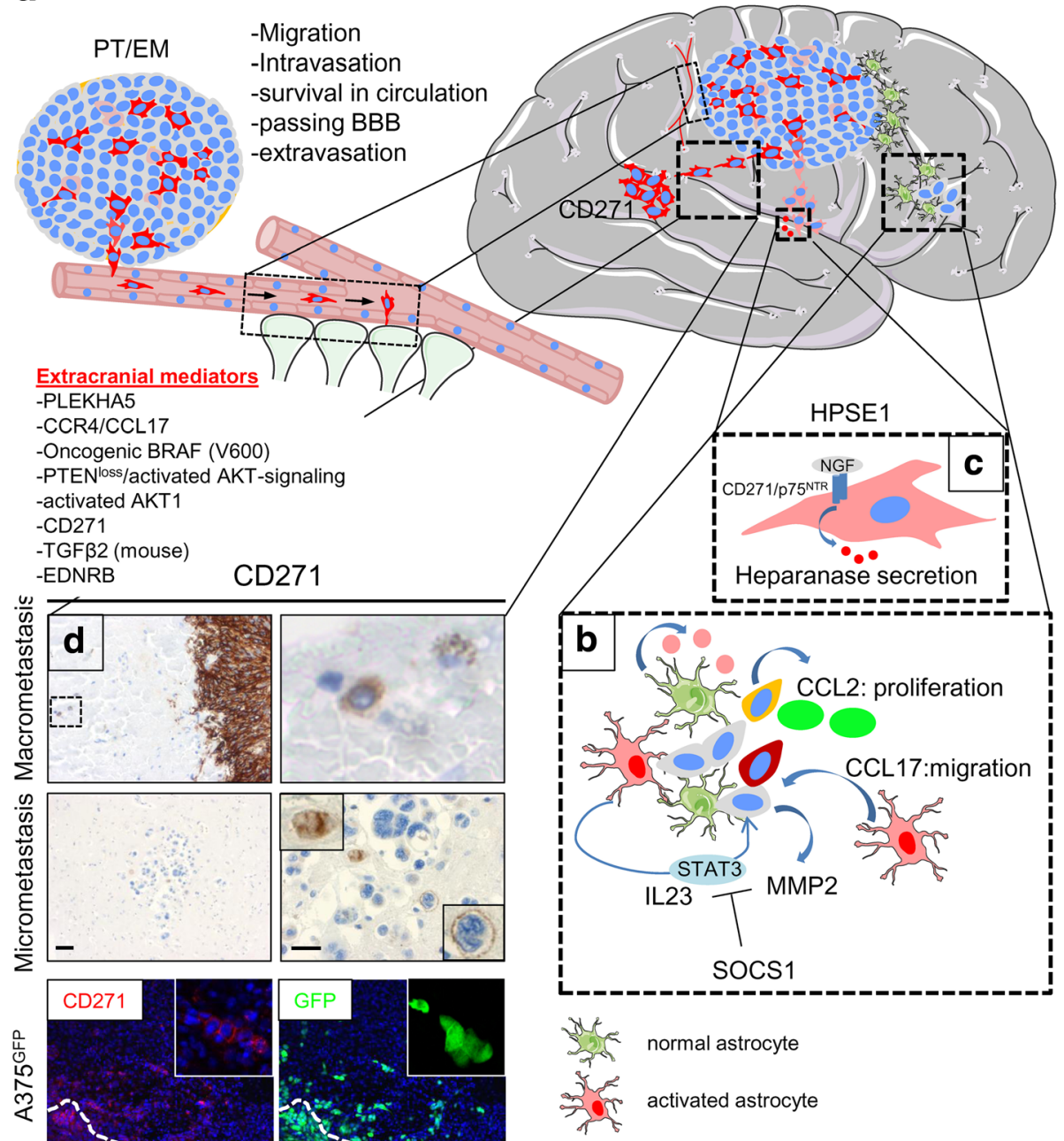

Brain-metastatic melanoma cell (BMMC)

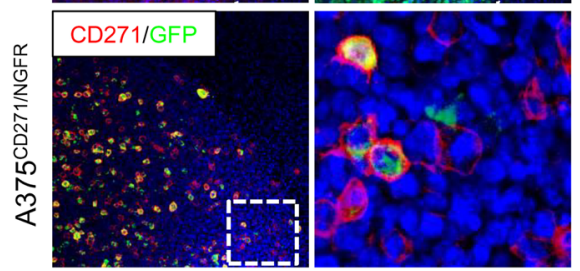

PTEN'ow BMMC

CCR4 ${ }^{+}$cells

Exosomes with PTEN-targeting miRNAs

lba1+ myeloid cells

Fig. 2 The many routes to brain metastasis for melanoma. a Schematic representation of the dissemination of melanoma cells to the brain. Important factors are the Pleckstrin Homology Domain Containing, Family A Member 5 (PLEKHA5), which mediates cells' transmigration through the BBB and the chemokine receptor CCR4 and its ligand CCL17. CCR4 ${ }^{+}$melanoma cells are probably "homed" to the brain by astrocyte-secreted CCL17; loss of the Phosphatase and Tensin Homolog (PTEN) is frequently observed and leads to hyperactivation of the PI3K/AKT pathway, which can be mimicked by the forced expression of activated AKT1. CD271 may serve as both a "homing" receptor that guides melanoma cells to the brain and a survival factor. Following migration to and intravasation into blood vessels, melanoma cells disseminate either hematogeneously or via lymphatic vessels (not shown). Cells which survive passage through the circulation need to transmigrate through the BBB through a process such as disrupting endothelial tight junctions or secreting of proteolytic enzymes. The BBB is composed of tightly connected endothelial cells which are in close proximity to perivascular endfeet of astrocytes. $\mathbf{b}$ In the brain, activated astrocytes secrete IL23 or CCL17 or exosome-loaded PTEN targeting miRNAs. The binding of IL23 to the receptor heterodimer IL23R/L12Rß1 induces STAT3 phosphorylation and expression of MMP2. Secreted CCL17 attracts CCR4 ${ }^{+}$melanoma cells and CCL17 binding to CCR4 induces the expression of MMP13 through NFkB. The loss of PTEN in brain metastatic melanoma cells induces the secretion of CCL2 which in turn leads to the recruitment of Iba1 ${ }^{+}$myeloid cells. The latter promote the proliferation of brain metastatic melanoma cells. Expression of the negative regulator of STAT-signaling SOCS1 (suppressor of cytokine signaling 1) was down-regulated in melanoma BM. c Cerebral migration of melanoma cells is facilitated through the binding of pro-NGF to the NGF-receptor (CD271, NGFR, p75 NTR) and the secretion of HPSE1. d Upper panels: CD271+ cells were found in brain micro- and macro-metastases. Lower panels: Brain slice cultures of $\mathrm{A} 375^{\mathrm{GFP}}$ or $\mathrm{A} 375^{\mathrm{CD} 271 \mathrm{NGFR}}$ cells revealed an extensive migration of melanoma cells with endogenous or stable forced expression of CD271 
with V600E and V600K as the most prevalent forms (75.4 and 17.2\%) [35]. In addition, the frequency of BRAF or NRAS mutations shows a melanoma subtype and metastatic site dependency [36]. Hence, BRAF/ NRAS mutations were more frequently observed in lymph nodes or brain sites (62 and 70\%) or non-acral cutaneous $(51.4 \%)$ than acral melanomas (16.2\%) [35].

In 2009, Dankort et al. established a mouse model system to decipher mechanisms of melanoma initiation and progression. They found that the expression of constitutively active $\mathrm{BRAF}^{\mathrm{V} 600 \mathrm{E}}$ under the control of the tyrosinase (TYR)-promoter, which occurs specifically in melanocytes [37], led to melanoma formation only in conjunction with the deletion of the inhibitor of PI3K-activation, PTEN (Phosphatase and Tensin Homo$\log$ ) [38]. This suggests that neither oncogenic BRAF nor the hyperactivation of PI3K/AKT signaling by PTEN loss [39] is sufficient to initiate melanoma formation alone. The overactivation of PI3K/AKT signaling triggers the activation of the mTOR (mammalian target of rapamycin)-pathway. Given this scenario, the administration of rapamycin ought to reduce melanoma formation, as demonstrated by Stambolic et al. The concerted action of activated AKT1 and BRAF ${ }^{\mathrm{V} 600 \mathrm{E}}$ in CDKN2A ${ }^{\text {loss }}$ melanoma also promotes lung and brain metastasis [40]. The further loss of PTEN protein expression is significantly correlated with a decrease in overall survival (OS) and a reduction in the time it takes for brain metastases to arise in stage IIIB/C melanoma patients with BRAF (V600) mutations [41]. These data suggest that oncogenic BRAF and activation of PI3K/AKT signaling are probably prerequisites for brain metastasis formation and may occur together. This is supported by the findings of Davies et al., who demonstrated that the activation of PI3K/AKT signaling occurs in distinct ways depending on whether the tumor exhibits an oncogenic mutation in BRAF vs. NRAS. BRAF-mutated tumors expressed low levels of PTEN accompanied by a high activation of AKT through phosphorylation. NRAS-mutated tumors, on the other hand, displayed a normal expression of PTEN but a low level of activated AKT (p-AKT) [42]. However, Davies et al., did not detect a significant difference in CNS involvement among Stage III patients with high levels of p-AKT/low PTEN [42]. Furthermore, a study by Jakob et al. demonstrated that patients with BRAF or NRAS mutated stage IV melanoma show a higher incidence for brain metastases at initial diagnosis as compared to patients carrying none of the mutations [43]. In contrast, the retrospective correlation of clinical parameters with the mutational status of BRAF, NRAS and KIT of 823 patients with melanoma and brain metastases diagnosed between 2006 and 2015 revealed that the time from primary diagnosis to brain metastasis did not vary by mutation and was not associated with survival after the diagnosis of brain metastases [44].
Hence, the information about the presence or absence of a certain mutation in BRAF or NRAS or KIT is not sufficient to predict whether or not a melanoma cell will enter the brain. The consequence of the presence of a specific mutation e.g. in BRAF is very likely determined by other, additional factors e.g. the activation of the PI3K/AKT pathway. The comparison of concordant brain and extracranial metastases revealed that brain metastases have a higher level of activated AKT and a lower expression of PTEN than metastases in the lung or liver [42, 45]. Thus active PI3K/AKT signaling appears to play a pivotal role in brain metastases that arise from melanoma (Fig. 2a-b) and distinguishes them from extracranial metastases while the status of 154 previously reported hotspot mutations was comparable in both matched tumor pairs [46].

This makes it likely that different mechanisms are involved, predetermined by the oncogenic mutation that is present, albeit mutations in passanger genes might also play a role in that process $[47,48]$. In addition a comparative analysis of matched pairs of brain and extracranial metastases, using Sequenom mass array-based genotyping, suggested that additional factors determine the fates of systemically disseminated melanoma cells, upon an examination for 154 known hotspot mutations of tumor specimens [46]. Furthermore, Chen et al. observed a high concordance between brain and extracranial metastases and suggested that brain metastasis is encoded in mechanisms that are independent of the mutation or variations in the copy number.

\section{Signaling processes that mediate brain metastasis - the role of the brain microenvironment PI3K/AKT, STAT3 and TGF $\beta$ signaling in brain metastasis}

Besides mutation-driven, intrinsically activated signaling pathways, a number of studies have demonstrated that the mutations found in extracranial and BM typically match $[45,46,49]$. While the mutational load of the two types of metastases is usually comparable, different signaling pathways are activated, suggesting that soluble factors provided by brain parenchyma cells such as astrocytes are crucial in the establishment of the new tumors. Such cells arise from a glial-restricted progenitor cell, and normally they play roles in the repair of brain tissue and scarring following injuries [50]. Astrocyte-secreted factors include neurotrophins (NGF, BDNF), [51], interleukins (IL-6, IL-8) and G-CSF [52]. These and other factors may be responsible for the hyperactivation of PI3K/AKT signaling in brain tumor cells [45], which would mean that brain parenchymal cells play a crucial role in the establishment and maintenance of BM. Maintenance is partially achieved through the emergence of stem-like cells [21,53].

Zhang et al. made the intriguing finding that when PTEN is expressed at normal levels in primary tumor 
cells, its expression is lost after dissemination to the brain, but not to other organs [54]. This mechanism is reversible and relies on interactions between brain metastatic cells and astrocytes, which release exosomes containing PTEN-targeting miRNAs in addition to cytokines and growth factors (Fig. 2b). The transfer of such exosomes to brain metastatic cells lowers PTEN expression while increasing the secretion of CCL2, which in turn leads to the recruitment of Iba1/AIF $1^{+}$myeloid cells. These reciprocally enhance the survival and proliferation of metastatic tumor cells in the brain [54]. Further evidence for this mechanism was gathered by intracranial injection of an astrocyte-specific Cre-adenovirus into Mirc1tm1.1Tyj/J mice. The adenovirus mediated a knock out of the miR-17-92 allele which is responsible for PTEN repression [55]. The astrocyte-specific ablation of PTEN-targeting miRNAs significantly suppressed brain metastasis of intracarotidly injected B16BL6 cells alongside with a restoration of PTEN and a strong reduction in CCL2 secretion.

To globally dissect stromal-cell driven changes of gene expression in tumors, Park et al. performed microarray-based profiling of highly metastatic and invasive A375SM cells that had been engrafted into the brains of recipient mice [56]. Microarrays with high species-specificity permitted to distinguish changes in gene expression induced by reciprocal interactions of mouse brain parenchyma from those induced by the human tumor cells. Profiling the gene expression in A375SM cells following intracranial transplantation revealed that mouse brain parenchyma cells induced neurological signaling processes including axonal guidance and glutamate receptor signaling. This revealed that in the brain microenvironment, cancer cells acquire the characteristics of the neuronal lineage. This stroma-induced reprogramming of brain tumor cells was also observed in co-cultures with astrocytes. Park et al. suggested that the acquisition of neuronal transcriptional patterns might play a role in the acquisition of chemoresistance among the brain metastases [56]. This is in agreement with a study by Lin et al., which suggested that astrocytes and melanoma cells physically interact via a gap junction-based communication, which in turn mediates chemoresistance among the melanoma cells [57].

\section{Extracranial signaling processes that mediate brain metastasis}

Extracranial metastases from melanomas can be distinguished into two groups: the cerebrotropic tumors, which tend to metastasize early ( $\leq 6$ months) and the non-cerebrotropic tumors which do not form brain metastases (>18 months) [58]. Jilaveanu et al. observed a high expression of the guanine nucleotide exchange factor PLEKHA5 in cerebrotropic patients and an A375 derivative with a high brain colonizing tendency
(A375Br) than in non-cerebrotropic tumors or cells (A375P). In all specimens of tumors from patients, however, PLEKHA5 was high - regardless of the anatomical location [58], albeit the knock-down of PLEKHA5 diminished the proliferation and transmigration of cerebrotropic cells across the BBB in an in vitro model [58]. This suggests that the expression of PLEKHA5 may permit melanoma cells to pass the blood-brain barrier efficiently [59]. PLEKHA5 specifically interacts with phosphoinositides and thus might modulate PI3K/AKT signaling by functionally interfering with mechanisms responsible for their activation [60]. Using the same cell lines, Xie et al. found that the expression of activated (phosphorylated) STAT3 was higher in BM than in primary tumors [61]. Using promoter assays with either a constitutively activated or a dominant negative form of STAT3, they also demonstrated that this transcription factor was responsible for the expression of MMP2, FGF2 and VEGF [61]. This indicated that STAT3-dependent signaling played a role in regulating processes that mediate the invasion and angiogenesis of metastatic melanoma cells to the brain. They also found an association between STAT3 activation and an increase in the number of lung metastases. This suggests that STAT3 activation may be responsible for co-occurrence of lung and brain metastases that has been observed in a study of 216 autopsied tumor specimens [62]. Mechanistically, an elevation in STAT3 signaling was linked to the loss of expression of the suppressor of cytokine signaling-1 (SOCS-1) or IL-23 induced signaling $[63,64]$. However, a recent tissue microarray study revealed that the level of activated STAT3 was not associated with an increased risk of developing $\mathrm{CNS}$ metastasis or time to CNS metastasis. The study included extracranial metastases of patients who did not have CNS metastasis at the time of the last follow-up. In contrast, STAT3 phosphorylation turned out to be a negative prognostic factor for overall survival (OS) in patients that did not develop CNS metastasis [65].

In addition, the expression of the TGF $\beta$-receptor ligand TGF $\beta 2$ seems to play a critical role in site-specific brain metastasis, as demonstrated by Zhang et al. in a mouse model. Patterns of TGF $\beta 2$ expression were sufficient to spatially distinguish brain metastases arising from the B16 and K-1735 murine melanoma cell lines. Whereas B16 cells with a low expression of TGF $\beta 2$ formed leptomeningeal metastases, overexpressing TGF $\beta 2$ in these cells led to the formation of metastases in the brain parenchyma, as was the case for K-1734 cells with high levels of endogenous TGF $\beta 2[66,67]$. Knocking down TGF $\beta 2$ reduced the number of K-1734 metastases to the brain parenchyma. This supports the idea that levels of TGF $\beta 2$ play a pivotal role in the spatial distribution of $\mathrm{BM}$, but the precise role of TGF $\beta$ 
signaling in this process has yet to be deciphered for human melanoma. In addition, expression of the G protein-coupled receptor EDNRB (endothelin receptor B) was associated with spontaneous melanoma cell brain metastasis in a murine model system. In addition, the overexpression of EDNRB increased the metastatic aggressiveness and decreased median survival as a result of advanced metastatic disease to lungs [68].

\section{Chemokines and chemokine receptors in brain metastasis}

Müller et al. identified chemokine receptors and their ligands as mediators of the organ-specific guidance of metastatic cells in breast cancer [69]. Very recently, Klein et al. showed that CCR4 and its ligand CCL17 play a pivotal role in brain metastatic cells derived from melanoma. Forcing the expression of CCR4 in melanoma cells increased their tumorigenicity and the number of brain metastases [70]. This was confirmed in an antibody-based neutralization of CCL17 in vitro, which attenuated melanoma cell migration and transendothelial migration. CCL17 and CCL22, another CCR4 ligand, are secreted by human endothelial cells, astrocytes and microglia. They may serve as chemo-attractants to guide $\mathrm{CCR}^{+}$melanoma cells to the brain (Fig. 2b) [70], potentially facilitating the formation of multiple BM. This seems to be supported by the fact that the matrix-metalloproteinase 13 (MMP13) is induced by CCR4 in an ERK/NFKB-dependent manner, facilitating invasiveness [71] or migration of colorectal cancer cells through CCR4/CCL17-mediated Rho-kinase signaling [72]. Klein et al. further demonstrated that brain-metastasizing melanoma cells can reprogram astrocytes to express the pro-inflammatory cytokine IL-23. This leads to an up-regulation of MMP2 (Figs. 2b, 3a) and enhanced melanoma cell migration and invasion [73]. Moreover, melanoma micrometastases are also capable of instigating astrogliosis and neuroinflammation, which increases the recruitment of activated astrocytes and further promotes the growth of micrometastatic cells. This seems to be a prerequisite for the establishment of macrometastases [74].

In summary, these data strongly suggest that the brain microenvironment not only attracts a specific subset of melanoma cells but also powerfully determines their fates and subsequent growth, migration and intracranial dissemination. The enhancement of PI3K/AKT, STAT3, TGF $\beta / S M A D$, chemokines and other signaling processes appears to cause a shift in the phenotype of melanoma cells that permits their metastasis to the brain.

\section{CD271 in melanoma cell migration and brain metastasis}

Melanocytes and similar melanoma cells arise from a population of multipotent cells in the neural crest (NC) which normally give rise to healthy neurons, glial cells and astrocytes [75]. Melanoma cells retain the expression of neural crest stem cell (NCSC) genes such as SOX10 [76] and other cellular properties of SC, including plasticity and the capacity to migrate [77, 78]. This tends to support the claim that melanoma cells might be guided ("homed") by growth factors and cytokines supplied by the brain parenchyma. This was established over a decade ago through studies which demonstrated that the nerve growth factor receptor CD271 (NGFR, $\mathrm{p} 75^{\mathrm{NTR}}$ ) and receptor ligands such as brain-derived neurotrophic factor (BDNF), nerve growth factor (NGF) and neurotrophin 3 or 4/5 (NTR3, NTR4/5) are involved in the mediation of brain metastases and enhanced survival $[79,80]$.

Shonukan et al. provided the first evidence that CD271 expression played a role in the migration of melanoma cells, demonstrating that the actin-bundling protein fascin (FSCN1) specifically interacts with CD271 and the actin cytoskeleton in an NGF-dependent manner [81]. This followed work that had been carried out almost a decade earlier by Menter et al., who observed that the expression of the low-affinity p75 neurotrophin receptor (CD271) in human melanoma cells was correlated to their potential to metastasize to the brain [82]. In 1996 Marchetti et al. further demonstrated that treatment with NGF increased the invasive properties of early-passage human brain-metastatic $70 \mathrm{~W}$ melanoma cells in vitro but had no effect on the metastasis of melanoma cells to other sites or the behavior of non-metastatic melanoma cells. They traced the heightened invasiveness to increases in the secretion of the proteolytic enzyme heparanase (HPSE1), triggered by pro-NGF and NT-3 (Fig. 2c) [83]. HPSE1 in turn was reported to induce AKT-signaling and probably promote tumor cell migration [84]. Furthermore, an exploration of human melanoma extracranial and BM revealed a predominant expression of CD271 in BM [85].

Most recent explorations of the functional role of CD271 in melanoma have clearly demonstrated that $\mathrm{CD}_{271^{+}}$cells comprise a special subtype of melanoma cells with stem-like properties and a lower expression of melanocyte-markers such as MART1, MITF and tyrosinase $[86,87]$. Further support for a crucial role of this receptor in melanoma cell migration came from studies in which CD271 was knocked down, compared to the effects when levels of the endogenous form were high or the molecule was overexpressed [21, 88]. Further studies of $\mathrm{BM}$ revealed the presence of migrating $\mathrm{CD} 271^{+}$cells in macro- and micrometastases (Fig. 2d, upper panels). Additional evidence came from serial confocal imaging of brain slice cultures of A375 ${ }^{\mathrm{GFP}}$ cells, which had a high propensity to migrate, and the $\mathrm{CD} 271^{+}$cells localized to the migration front (Fig. 2d, center panels). A study 


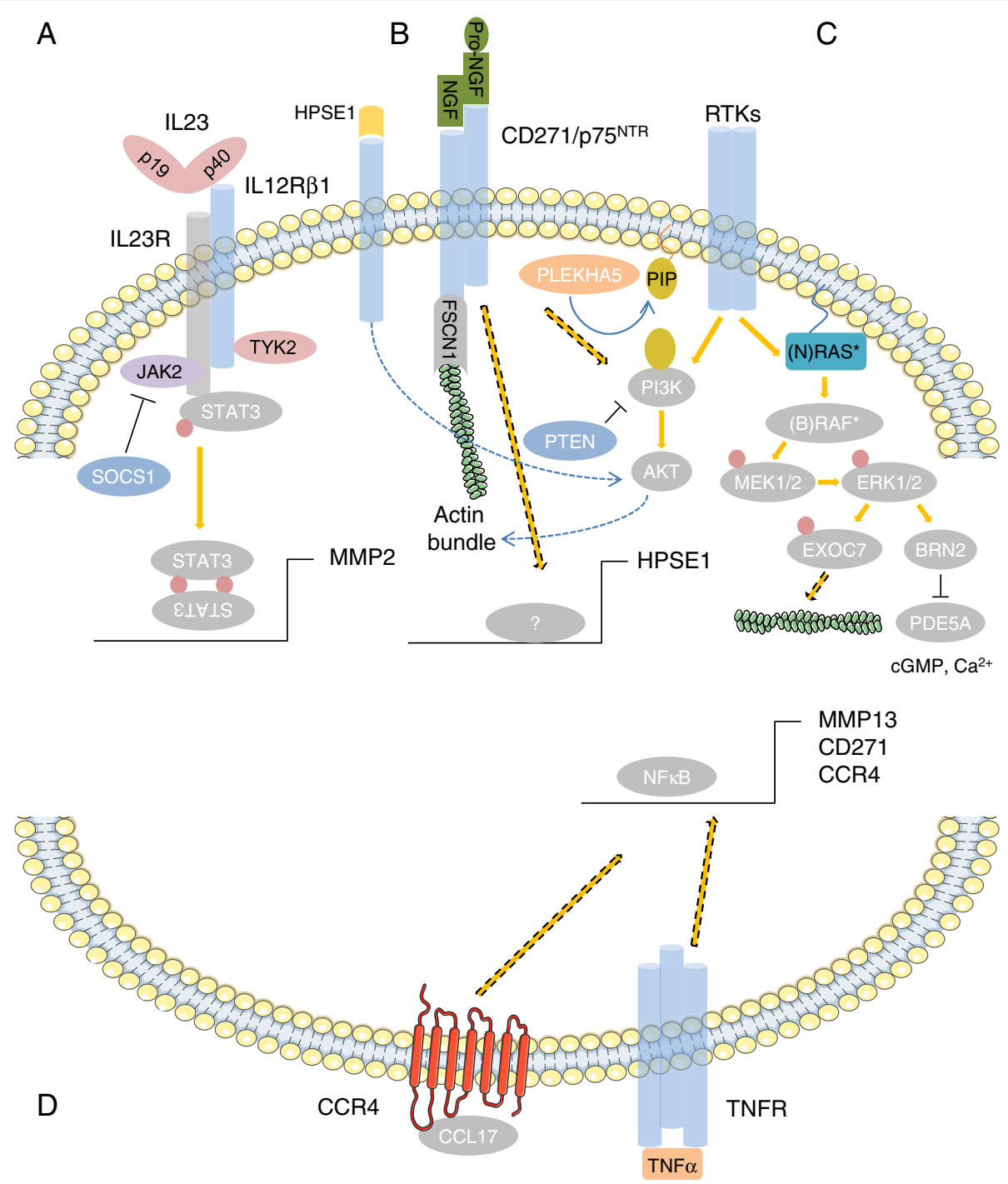

Fig. 3 Simplified scheme of signaling pathways and molecules mediating the formation of brain metastases from melanoma. a Activation of STAT3 in BM can occur via astrocyte-secreted heterodimeric IL23 and leads to the expression of MMP2. The suppressor of cytokine signaling 1 (SOCS1) binds to and inhibits the kinase activity of Janus-kinase 2 (JAK2). The loss or downregulation of SOCS2 in BM may be responsible for increased stat3 activation. $\mathbf{b}$ Binding of NGF or pro-NGF induces CD271/p75 NTR -mediated FSCN1 binding or HPSE1 secretion or PI3K/AKT signaling via unknown effectors. c RTKs induce PI3KJAKT signaling or the RAS/RAF cascade. Mutually exclusive mutant $(*)$ RAS $(\sim 15-20 \%$ NRAS mutations) or RAF ( 40-50\% BRAF mutations) activate the extracellular-regulated kinases ERK1/2, which in turn phosphorylate exo70/EXOC7 (filled red circle), the catalytic subunit of the exocyst complex, or blocks expression of PDE5A via brain-2 (BRN2/POU3F2) to regulate actin dynamics. HPSE1 activity induces AKT-signaling, blocked by PTEN or modified by PLEKHA5. $\mathbf{d}$ The secretion of CCL17 by astrocytes attracts CCR4 ${ }^{+}$ melanoma cells, possibly inducing NFKB-mediated signaling and the regulation of MMP13, CD271 or CCR4 which is in turn regulated via TNFa

tracing A375 ${ }^{\mathrm{CD} 271 / \mathrm{NGFR}}$ cells clearly demonstrated that cells which stably expressed CD271, hence the level of CD271 was not affected by cellular plasticity, were capable of migration (Fig. 2d, lower panels). These pieces of evidence suggest that melanoma cells very likely express CD271 before colonizing the brain and that this may even be required for their invasive behavior. The stable expression of CD271 enhanced the migratory phenotype even of A375 cells [88], which is intrinsically mediated by oncogenic BRAF via the phosphorylation of cortactin and the exocyst subunit Exo70 [89] and through the ERK1/2-mediated downregulation of the cGMP-specific phosphodiesterase PDE5A [90]. Down regulation of PDE5A in turn increases levels of cGMP and $\mathrm{Ca}^{2+}$, regulates actin dynamics and contractility and MMP secretion in melanoma cells. In A375 cells, the migration is probably enhanced by the CD271-dependent expression of genes associated with 
migration, such as the hyaluronan-mediated motility receptor (HMMR) or fibroblast growth factor 13 (FGF13), which is not secreted but stabilizes microtubules [21, 88, 91].

Additional work on the $\mathrm{BM}$ revealed that a subset of the tumors had high levels of CD271 that clearly distinguished them from a CD271 ${ }^{\text {low }}$ subset. A comparative analysis of publicly available expression data from BM (GSE50493, GSE44660) revealed that CD271 expression was indeed sufficient to characterize BM. CD271 ${ }^{\text {high }}$ BM showed a high expression of genes associated with a neural-crest stem-like phenotype and higher levels of DNA-repair genes but a low expression of MITF and its targets among them MET, MLANA or TYR compared to CD271 ${ }^{\text {low }}$ BM [21] (Fig. 4a-c, left panel). Recently, the expression of the melanocyte-specific markers MITF, MLANA and TYR has been associated with a highly proliferative melanoma cell phenotype that metastasizes to multiple organs. The expression of the receptor tyrosine kinase (RTK) AXL, on the other hand, was associated with a type of melanoma cell that was highly invasive but much less proliferative, and predominantly metastasized to the brain [92, 93]. AXL expression was significantly increased in CD271 ${ }^{\text {high }}$ BM [21], in line with previous observations that these metastatic cells have a slow cycle and proliferate at low rates $[78,94]$. Data on the two subtypes suggests that CD271 indirectly regulates mediators of the phenotype of brain-metastasizing melanoma cells (Fig. 4b, lower panel).

\section{Therapeutic approaches to brain metastases from melanoma}

Melanoma patients with brain metastases have a median overall survival (OS) of 2.5-6 months [95] which can be attributed to the difficulty of delivering therapeutic drugs to primary and secondary brain tumors, reviewed in [96], and the fact that BM feature a highly invasive and migratory phenotype $[16,32]$.

\section{Systemic therapeutics - chemotherapeutic interventions}

Prior to the development of targeted and immunomodulatory therapies, the most clinically relevant approaches to treatment involved chemotherapeutics with dacarbazine (DTIC) as the standard of care for most patients, approved by the FDA in 1975. However, DTIC is incapable of penetrating the blood-brain barrier, hence ineffective in brain metastases [97]. The administration of fotemustine vs. DTIC achieved an improved best overall response rate (BORR) of $15.2 \%$ vs. $6.8 \%$. However, the median time to the development of brain metastases was 22.7 months with fotemustine v.s. 7.2 months with DTIC [98]. Switching to TMZ led to high CNS penetrance, but the overall effects remained comparable to those of DTIC $[99,100]$. In summary, chemotherapeutic drugs were unable to achieve major improvements in the overall survival of patients; as a result, the current trend has been to replace them with immunomodulatory drugs, particularly for tumors that do not exhibit druggable mutations.

\section{Targeting therapeutics - immune checkpoint and small molecule inhibitors}

Following migration to blood vessels and intravasation, metastatic melanoma cells must escape immune surveillance to survive, extravasate and enter the brain [101]. This evasive capacity is generally mediated by the activation of immune suppressive regulatory T-cells (Tregs) by tumor cells through, for example, the secretion of TGF $\beta$, reviewed in [102]. Tregs accumulate in melanoma, which also exhibit an enrichment of activated CD8 ${ }^{+}$T-cells [103] and the ratio of CD8-positive $\mathrm{T}$ cells versus Treg has been found to be a predictor for melanoma patient survival [104]. CD8 ${ }^{+}$ T-cells secrete pro-inflammatory cytokines to induce yet another means by which tumor cells evade immune surveillance, involving the up-regulation of programmed cell death-ligand 1 (PD-L1), [103]. PD-L1 binds to the receptor PD-1, expressed on T cells, leading to a reduction in target cell activation [105]. Soluble PD-L1 has been identified as a biomarker for melanoma [106], which hints that a low expression of PD-L1 and PD-L2 might be correlated with favorable patient outcomes. But the expression of PD-1 ligands is restricted to certain melanoma cell subtypes [107]. In the clinic, neutralizing antibodies blocking the interaction of PD-L1 (Pembrolizumab [108], Nivolumab [109]) with PD1, albeit their efficacy remains controversial [110]. A recent study by Goldberg et al. (two-cohort, phase II, clinical trial NCT02085070) revealed that BM from melanoma exhibited partial or complete responses (22\%) to pembrolizumab [111]. But the high number of patients whose metastases failed to respond suggests that in many cases, melanoma cells take advantage of additional defense mechanisms that have yet to be identified.

The immune suppression of Tregs is further mediated by their expression of the cytotoxic T-lymphocyte-associated antigen 4 (CTLA-4) and its binding to CD80/CD86, reviewed in [112]). The therapeutic application of the neutralizing antibody ipilimumab yet represents another mechanism of activation of the immune system to fight against tumor cells. The overall survival of patients with visceral metastases (M1c stage) who received ipilimumab was improved (10.1 months) compared to a control group administered a gp100 peptide vaccine (6.4 months) (NCT00094653, Additional file 1: Table S1) [113].

Peritumoral edema is frequently observed alongside with brain metastases formation, leading to increased intracranial pressure and neurological disturbances; 


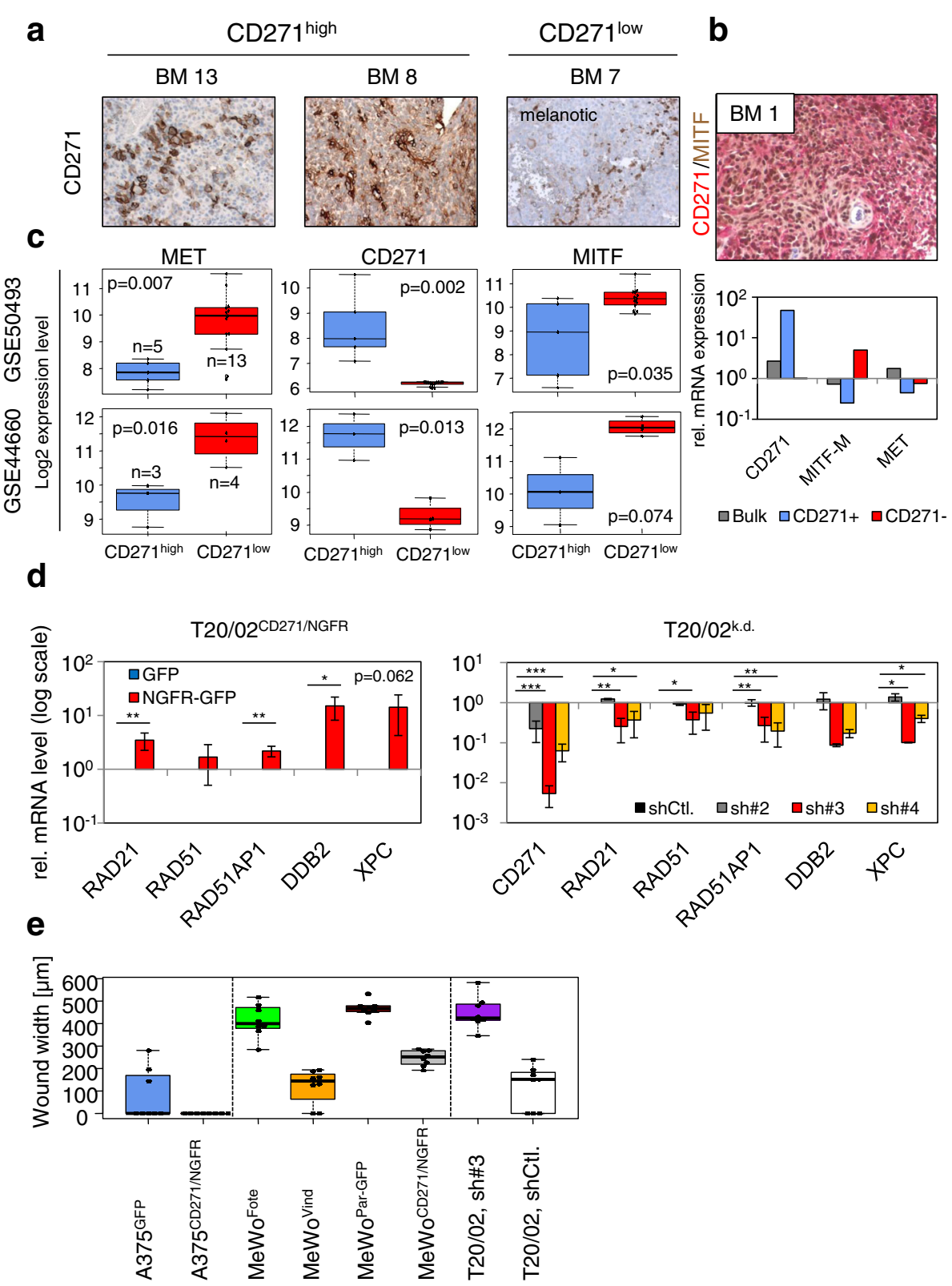

Fig. 4 The expression of $C D 271$ determines melanoma cell properties. a Expression of CD271 in two representative $C D 271^{\text {high }}$ brain metastases $(\mathrm{BM} ; 13,8)$ as well of a melanotic CD271 low BM (7), as determined by immunohistochemistry. $\mathbf{b}$ Upper panel: Co-staining of CD271 (red) and MITF (brown) of a CD271 ${ }^{\text {high }}$ BM (1). Lower panel: relative expression of CD271, MITF-M or MET in melanoma cells either positively $\left(C D 271^{+}\right.$) or negatively $\left({ }^{\left(C D 271^{-}\right.}\right.$) sorted for CD271 or unsorted (Bulk). $\mathbf{c}$ Levels of expression of MET, CD271 and MITF-M in CD271 ${ }^{\text {high }}$ and CD271 ${ }^{\text {low }}$ BM from two independent studies (GSE50493 and GSE44660). P-values were determined using the Wilcoxon rank sum test. $\mathbf{d}$ CD271-dependent regulation of DNA-repair genes in

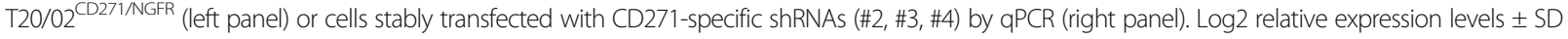
of independent triplicates, compared to cells either expressing GFP or knock-down controls (shCtl.) are shown. ${ }^{*} p \leq 0.05 ;{ }^{* *} p \leq 0.01 ;{ }^{* * *} p \leq 0.001$. e Melanoma cells (A375, MeWo) engineered to stably express CD271 and drug-resistant (Fote, Vind) cells show a higher migratory than control cells (GFP). Contrary, the CD271 knock-down (sh\#3) strongly decreased cell migration as determined by Live-cell imaging-based scratch-wound assays. Wound closure is indicated by the wound width in $\mu \mathrm{m}$

symptoms are controlled by administration of corticosteroids [114]. Margolin et al. assessed the efficacy of ipilimumab in patients with either asymptomatic or symptomatic brain metastases who had not or had received corticosteroid treatment at study entry. The study revealed that ipilimumab elicited a disease control in $24 \%$ of patients with small and asymptomatic brain metastases, whereas $10 \%$ of patients with symptomatic brain metastases, received a disease control within 12 months (NCT00623766, Additional 
file 1: Table S1, Metadata 1 and 2) [115]. Hence, patients with larger and symptomatic brain metastases who require oral steroids to control peritumoral edema have an ongoing poor response to systemic therapy and are mostly excluded from clinical trials. Therefore, other treatment strategies improving the outcome of these patients are needed e.g. the combination of ipilimumab and the VEGF-neutralizing antibody bevacizumab, a combination which was successfully tested in glioblastoma [116].

Overall, 26\% of patients exhibited a refractory response to ipilimumab, and hence might benefit from PD1 inhibitor therapies [108, 117]. A case which has been more comprehensively discussed elsewhere [118, 119].

Strikingly, a dual strategy that used a combination of ipilimumab and nivolumab to block PD1 and CTLA4-mediated immune suppression evoked an intracranial objective response rate of $56 \%$, as demonstrated by Tawbi et al. [120]. And a multicenter US trial (CheckMate204 study, NCT02320058) of melanoma patients with one or more brain metastases achieved a complete response $(\mathrm{CR})$ in $19 \%$ of patients; in these cases, the intracranial and extracranial responses largely overlapped. In addition, the survival of patients who received ipilimumab either prior to SRS or thereafter was significantly improved over that of patients who received SRS alone (19.9 months vs. 4.0 months; $P=0.009)$, [121]. Recently, a multicentre open-label randomized phase 2 trial (ABC, NCT02374242, Additional file 1: Table S1) by Long et al. [122] performed in three cohorts of immunotherapy-naive patients revealed an intracranial response to the combination of nivolumab+ipilimumab or nivolumab alone in $46 \%$ or $20 \%$ of patients with asymptomatic brain metastases with no previous local brain therapy, respectively. The intracranial complete response to nivolumab+ipilimumab or nivolumab alone was 17 and $12 \%$, respectively. However, the intracranial response was markedly reduced (6\%) in patients brain metastases in whom local therapy had failed, or who had neurological symptoms, or leptomeningeal disease.

These results clearly demonstrate that therapeutic interventions that block immune suppressive mechanisms are effective in brain metastases, however the identification of strategies for further improving the response to and efficacy of checkpoint inhibitors is mandatory and will provide more insight in the interaction of melanoma and immune cells. A very recent study uncovered the role of the oral and gut microbiome, discriminating melanoma patients who respond and those who do not respond to anti-PD-1 immunotherapy [123]. In addition, since the brain is immune privileged, extracranial and brain metastases very likely feature distinct immune evasion mechanisms. At least for brain metastases, microglia might play an important role. In breast cancer, microglia were associated forced brain metastasis [124].

The identification of mutations of BRAF in human cancers [125] is a milestone, opened new avenues in the therapy of melanoma and was a prerequisite for the development of small molecule BRAF inhibitors, most important vemurafenib and dabrafenib. Besides the high response rate of $53 \%$ of patients to vemurafenib accompanied by a median OS of 15.9 months [126], vemurafenib also induces clinical responses in melanoma brain metastases. Albeit, the access of vemurafenib to the brain is restricted by an ABCB1-mediated efflux [127]. Dummer et al. demonstrated in an open-label pilot study that $42 \%$ of patients showed an overall partial response (PR) to vemurafenib at both intracranial and extracranial sites, $38 \%$ achieved a stable disease and $37 \%$ of patients showed a remarkable $(>30 \%)$ regression of brain metastases [128]. In addition, a open-label, phase 2, multicentre study of 146 patients with or without previous vemurafenib treatment showed a intracranial BORR (best overall response rate) of $18 \%$ as assessed by an independent reviewer committe (IRC). However, $32 \%$ or $34 \%$ of patients progressed in cohorts without or with previous treatments, respectively [129]. Furthermore, the BREAK-MB trial (NCT01266967 and Additional file 1: Table S1) assessed the response of patients with confirmed BRAFV600E/K mutations to dabrafenib. The study revealed that patients who either had or had not received previous local treatment for brain metastases and progressive brain metastases after previous local treatments showed an intracranial response of $39.2 \%$ or $30.8 \%$, respectively. Hence, dabrafenib was effective in brain metastases irrespective of whether they were untreated or have been previously treated and progressed [130]. The intracranial response of patients who either had or had not received previous local treatment for brain metastases was further increased by the combination of dabrafenib and trametinib (56\% vs. 58\%) in the COMBI-MB study (NCT02039947, Additional file 1: Table S1) [20]. However, the median duration of response was relatively short and might reflect the different modes of activation of signaling pathways and molecular profiles of melanoma brain and extracranial metastases [46].

In summary, targeting therapies have significantly improved the outcome of patients both with extracranial and brain metastases. However, their impact and efficacy might depend on the spatial distribution of metastases.

\section{Radiosurgery}

Single metastases that occur in accessible areas of the brain can be resected or successfully treated with stereotactic radiosurgery (SRS) using gamma or cyber knifes, minimal invasive state-of-the-art techniques which have 
proven more effective than whole brain radiotherapy (WBRT) in extending OS, with the median reaching 13.9 months [131-133]. Both, WBRT and SRS are associated with severe side effects, most important adverse neurocognitive effects for patients who received WBRT as well as radiation necrosis which is also common but more frequently observed in SRS patients (reviewed in [134]). Radiation necrosis is characterized by fibrinoid necrosis of small arteries and arterioles, likely induced by extensive damage to the vascular endothelium [135].

In a comprehensive clinical study of patients diagnosed with brain metastases from several cancer types except leptomeningeal disease, small-cell lung cancer and hematologic cancer surgical resection followed by SRS of the surgical cavity was proven more effective and significantly lowered local recurrence compared with patients with surgical resection alone (NCT00950001 and Additional file 1: Table S1) [136]. Initially, SRS or the combination of SRS + WBRT was associated with a higher local and distant control than observed for SRS alone, hence adopted to patients with a limited number (1-4) of brain metastases. Albeit this strategy did not improve OS (reviewed in [137]). A multicohort prospective study of 1194 patients with brain metastases of mainly breast and lung cancer, revealed that even in patients with multiple brain metastases (5-10) who had not received previous WBRT [132], SRS was as effective as in patients with 2-4 brain metastases.

To further increase the time to recurrence and improve melanoma patients survival, radiotherapy is combined with targeting drugs or immune checkpoint inhibitors, capable of passing the blood brain barrier. Currently, clinical trials combining ipilimumab and nivolumab with SRS (<5 progressing BM) or WBRT $(\geq 6$ progressing $\mathrm{BM})$ in melanoma patients are in progress (NCT03340129, NCT02097732 and Additional file 1: Table S1). In addition, a recent retrospective study revealed a high $(70 \%)$ complete or partial response (CR/ PR) to concurrent pembrolizumab and SRS [138]. However, the efficacy of these combinatorial trials needs to be proven more comprehensively. Since both extracranial metastases and $\mathrm{BM}$ also exhibit a broad response to vemurafenib, dabrafenib and other drugs targeting oncogenic BRAF [20, 129, 139, 140]. Dabrafenib has particularly potent effects on melanoma $\mathrm{BM}$ irrespective whether patients had received previous local treatment including surgical resection, WBRT, or SRT and progressed (clinical study NCT01266967) [130].

\section{The consequences of drug resistance}

Following a positive response towards BRAF-targeting drugs, tumor cells begin to exhibit resistance within 67 months [141]. This is marked by an up-regulation of receptor tyrosine kinase receptors PDGFRB [142] or
EGFR [143], signaling mediators such as CRAF or NRAS, and the acquisition of mutations in MEK1, MEK2 and NRAS that trigger a stimulation of the RAS/RAF/MAPK pathway (reviewed in [144]). This suggests that melanomas resistant to BRAF inhibitors might be treated with the potent MEK inhibitor trametinib [145]. However, the combination of dabrafenib and trametinib was only moderately effective in patients with BRAF inhibitor-resistant melanoma [146]. Nevertheless, the combination provoked a better response of intracranial BRAFV600-mutant brain metastases from melanoma (clinical trial NCT01266967) compared to monotherapies based on the BRAF inhibitor [130]. At this point another hurdle commonly appeared: cells developed resistance to MEK inhibitors, and the MAPK pathway was reactivated through an acquisition of MEK activating mutations [147] or BRAF gene amplification [148]. Furthermore, two recent studies reported increases in BM or a spontaneous formation of new lesions in patients being treated with vemurafenib [149, 150], most likely due to the mechanisms described above.

\section{Therapy-induced changes in the expression of markers}

Several lines of evidence suggest a therapy-induced enrichment for stem-like tumor cells a mechanism potentially responsible for therapeutic failures and tumor relapse. Kim et al. demonstrated that CD133 -a putative marker of melanoma-initiating cells [151,152]- acts in concert with the chemokine receptor CXCR4 to facilitate a metastatic phenotype [151]. The expression of CD133 (PROM1), was modified by drug-treatment. Furthermore, in glioblastoma, Bao et al. demonstrated a radiation-induced mechanism responsible for the enrichment of radio-resistant $\mathrm{CD} 133^{+}$ glioblastoma stem-like cells by activation of the DNA-damage response [153]. In addition, breast cancer-related BM [154] have been associated with a high expression of DNA repair genes and the activation of the PI3K/AKT signaling [155] pathway. These factors may also determine whether radiation therapy will be effective against BM arising from melanoma [156]. Alongside an increased capacity to repair DNA damage, metastatic cells may undergo drug-induced changes in gene expression that help account for their low response to chemotherapies. These therapies in particular induce a DNA damage response in the cells.

The expression of CD271, which is induced by DNA-damaging drugs, may serve as a critical factor in the regulation of DNA repair genes (Fig. 4d) and modifies the migratory phenotype of melanoma cells. Cell migration of melanoma cells was indeed modified in response to the levels of CD271. Hence, increased migration was observed for drug-resistant (Fote, Vind) cells or cells with forced expression of CD271 (NGFR/CD271) [88]. In contrast, the CD271 knock-down was accompanied by a marked reduction in migration [21], (Fig. 4e). Moreover, Lehraiki et al. 
demonstrated that $\mathrm{CD} 271$ promotes vemurafenib-resistance of A375 cells through a NFkB-regulated mechanism. Furthermore, the expression of CD271 was strongly increased in relapsed tumors [157].

Very recently Haueis and Imafuku et al. have reported that melanoma patients undergoing vemurafenib therapy develop more brain metastatic lesions/ tumors than those who do not receive the drug $[149,150]$. Along the same lines, Klein and Zubrilov et al. identified CCR4, JARID1B and CD271 among the top up-regulated genes in vemurafenib-resistant, brain metastatic melanoma cells $[70,158]$. This raises the provocative question of whether vemurafenib treatment enhances metastasis generally, or is an effect specific to BM in melanoma patients, potentially because the treatment induces the expression of metastasis-promoting factors. Seifert et al. investigated how melanoma metastases responded to vemurafenib in previously drug naive patients. They found that extracranial metastases were more prone to respond completely $(\mathrm{CR})$ or partially $(\mathrm{PR})$ than metastases of the brain or bone. Moreover, the brain was the most common site of progression for patients receiving vemurafenib; among patients who had previously developed brain metastases, $79 \%$ experienced a recurrence of $\mathrm{BM}$ [159]. The mechanisms responsible for the low response have not been fully elucidated. One suggestion from Seifert et al. is that growth factors from the cerebrospinal fluid (CSF) trigger PI3K/AKT signaling pathways, making BM resistant to vemurafenib [159]. This idea could explain the findings made by Haueis and Imafuku et al.

\section{Conclusion}

Diverse mediators and signaling pathways have been associated with the development of brain metastases in melanoma. While some of the mechanisms that help drive this process seem to be coming into focus, important questions remain: At what point during the disease do metastases develop? Do cells shed from extracranial metastases have a higher propensity to migrate to the brain than primary melanoma cells? If so, what factors might be responsible? A number of studies have suggested that therapeutic interventions frequently seem to have the negative consequence of selecting for cells with a stem-like phenotype. Targeting melanoma cells that express CD133, CD271 or ABCB5 has been shown to block processes of migration [160], metastasis [161] and tumor maintenance $[53,162]$. Hence, the combination of targeting small molecule inhibitors and/or immune checkpoint inhibitors with therapeutic interventions to eradicate stem-like cells e.g. siRNA-based strategies may suggest a possible way forward in hopes of further improving patient responses and overall survival.

\section{Additional file}

Additional file 1: Table S1. Clinical trials. Results of clinical trials as provided by (https://www.clinicaltrials.gov/) of melanoma patients with brain metastases are summarized. OS = overall survival, PFS = progression free survival, BORR = best overall response rate, assessed by IRC (independent reviewer commitee) is defined as percentage of participants who were responders [with best overall response (BOR) documented as confirmed complete response (CR) or partial response $(P R)] . \mathrm{OIR}=$ overall intracranial response, defined as the number of participants whose intracranial response was a confirmed complete response (CR) or partial response (PR) assessed by investigators using modified Response Evaluation Criteria in Solid Tumors (RECIST), version

1.1. Metadata 1: provides information about the therapeutic

interventions performed within the study as well as the study stage.

Metadata 2: provides detailed study data particularly drug applications as well as data additional data of NCT01378975, the time to the

development of new brain metastases in responders. (ZIP 25 kb)

\section{Abbreviations}

CCL: Chemokine (C-C morif) ligand; CCR: C-C chemokine receptor; CNS: Central nervous system; CR: Complete response; DTIC: Dacarbazine; ERK: Extracellular-signal regulated kinase; Fote: Fotemustine; MAPK: Mitogenactivated protein kinase; OS: Overall survival; PR: Partial response; SRS: stereotactic radiosurgery; Vind: Vindesine; WBRT: Whole brain radiotherapy

Funding

T.R. received funding by the Deutsche Forschungsgemeinschaft DFG (RE 4210/1-1).

\section{Author's contributions}

The authors read and approved the final manuscript.

Ethics approval and consent to participate

Not applicable.

Consent for publication

All authors agreed on the manuscript.

Competing interests

The author declares that he has no competing interests.

\section{Publisher's Note}

Springer Nature remains neutral with regard to jurisdictional claims in published maps and institutional affiliations.

Received: 1 November 2017 Accepted: 9 July 2018

Published online: 27 July 2018

\section{References}

1. Nieder C, Adam M, Astner ST. Disease presentation and outcome in young patients ( $<40$ years) with brain metastases from malignant melanoma. Anticancer Res. 2008:28:1325-7.

2. Raizer JJ, Hwu WJ, Panageas KS, Wilton A, Baldwin DE, Bailey E, von Althann C, Lamb LA, Alvarado G, Bilsky MH, Gutin PH. Brain and leptomeningeal metastases from cutaneous melanoma: survival outcomes based on clinical features. Neuro-Oncology. 2008;10:199-207.

3. Chiarion-Sileni V, Murr R, Pigozzo J, Sarti S, Tomassi O, Romanini A. Brain metastases from malignant melanoma. Forum (Genova). 2003;13: 170-82. quiz 190.

4. Cohn-Cedermark G, Mansson-Brahme E, Rutqvist LE, Larsson O, Johansson H, Ringborg U. Central nervous system metastases of cutaneous malignant melanoma--a population-based study. Acta Oncol. 1998;37:463-70.

5. Gottschalk J, Dopel SH, Schulz J, Fuchs M, Martin H. Significance of immunohistochemistry in neuro-oncology. $V$. Keratin as a marker for epithelial differentiation of primary and secondary intracranial and intraspinal tumors. Zentralbl Allg Pathol. 1987;133:133-45. 
6. Schouten LJ, Rutten J, Huveneers HA, Twijnstra A. Incidence of brain metastases in a cohort of patients with carcinoma of the breast, colon, kidney, and lung and melanoma. Cancer. 2002;94:2698-705.

7. Qian M, Ma MW, Fleming NH, Lackaye DJ, Hernando E, Osman I, Shao Y. Clinicopathological characteristics at primary melanoma diagnosis as risk factors for brain metastasis. Melanoma Res. 2013;23:461-7.

8. Hopkins S, Groman A, Saito N. Breslow Depth is a Risk Factor for Brain Metastases in Patients with Malignant Melanoma. Int J of Radiation Oncology • Biology • Physics. 2010;78(3):S292.

9. Gardner LJ, Ward M, Andtbacka RHI, Boucher KM, Bowen GM, Bowles TL, Cohen AL, Grossmann K, Hitchcock YJ, Holmen SL, et al. Risk factors for development of melanoma brain metastasis and disease progression: a single-center retrospective analysis. Melanoma Res. 2017;27:477-84.

10. Fidler IJ, Gruys E, Cifone MA, Barnes Z, Bucana C. Demonstration of multiple phenotypic diversity in a murine melanoma of recent origin. J Natl Cancer Inst. 1981;67:947-56.

11. Fidler IJ, Talmadge JE. Evidence that intravenously derived murine pulmonary melanoma metastases can originate from the expansion of a single tumor cell. Cancer Res. 1986:46:5167-71.

12. Labelle M, Hynes RO. The initial hours of metastasis: the importance of cooperative host-tumor cell interactions during hematogenous dissemination. Cancer Discov. 2012;2:1091-9.

13. Roesch A, Fukunaga-Kalabis M, Schmidt EC, Zabierowski SE, Brafford PA, Vultur A, Basu D, Gimotty P, Vogt T, Herlyn M. A temporarily distinct subpopulation of slow-cycling melanoma cells is required for continuous tumor growth. Cell. 2010;141:583-94.

14. Easwaran H, Tsai HC, Baylin SB. Cancer epigenetics: tumor heterogeneity, plasticity of stem-like states, and drug resistance. Mol Cell. 2014;54:716-27.

15. Deutsch GB, Tyrell R, Yost S, Deutsch MB, Barkhoudarian G, Kelly DF, Faries $M B$. Predicting the incidence and timing of central nervous system disease in metastatic melanoma: Implications for surveillance and preventative therapy. J Am Acad Dermatol. 2018;78:419-21.

16. Simonsen TG, Gaustad JV, Rofstad EK. Intertumor heterogeneity in vascularity and invasiveness of artificial melanoma brain metastases. J Exp Clin Cancer Res. 2015;34:150.

17. Davies MA, Liu P, Mclntyre S, Kim KB, Papadopoulos N, Hwu WJ, Hwu P, Bedikian A. Prognostic factors for survival in melanoma patients with brain metastases. Cancer. 2011:117:1687-96.

18. Hong AM, Suo C, Valenzuela M, Haydu LE, Jacobsen KD, Reisse CH, Fogarty G. Low incidence of melanoma brain metastasis in the hippocampus. Radiother Oncol. 2014;111:59-62.

19. Wu SG, Rao MY, Zhou J, Lin Q, Wang ZJ, Chen YX, He ZY. Distribution of metastatic disease in the brain in relation to the hippocampus: a retrospective single-center analysis of 6064 metastases in 632 patients. Oncotarget. 2015;6:44030-6.

20. Davies MA, Saiag P, Robert C, Grob JJ, Flaherty KT, Arance A, ChiarionSileni $V$, Thomas L, Lesimple T, Mortier L, et al. Dabrafenib plus trametinib in patients with BRAFV600-mutant melanoma brain metastases (COMBI-MB): a multicentre, multicohort, open-label, phase 2 trial. Lancet Oncol. 2017;18:863-73.

21. Radke J, Roßner F, Redmer T. CD271 determines migratory properties of melanoma cells. Sci Rep. 2017;7:9834.

22. Brastianos PK, Carter SL, Santagata S, Cahill DP, Taylor-Weiner A, Jones RT, Van Allen EM, Lawrence MS, Horowitz PM, Cibulskis $K$, et al. Genomic characterization of brain metastases reveals branched evolution and potential therapeutic targets. Cancer Discov. 2015;5: 1164-77.

23. Crone C. The permeability of brain capillaries to non-electrolytes. Acta Physiol Scand. 1965;64:407-17.

24. Abbott NJ, Ronnback L, Hansson E. Astrocyte-endothelial interactions at the blood-brain barrier. Nat Rev Neurosci. 2006;7:41-53.

25. Luissint AC, Artus C, Glacial F, Ganeshamoorthy K, Couraud PO. Tight junctions at the blood brain barrier: physiological architecture and diseaseassociated dysregulation. Fluids Barriers CNS. 2012:9:23.

26. Janzer RC, Raff MC. Astrocytes induce blood-brain barrier properties in endothelial cells. Nature. 1987:325:253-7.

27. Fazakas C, Wilhelm I, Nagyoszi P, Farkas AE, Hasko J, Molnar J, Bauer $\mathrm{H}$, Bauer HC, Ayaydin F, Dung NT, et al. Transmigration of melanoma cells through the blood-brain barrier: role of endothelial tight junctions and melanoma-released serine proteases. PLoS One. 2011;6: e20758.
28. Murry BP, Blust BE, Singh A, Foster TP, Marchetti D. Heparanase mechanisms of melanoma metastasis to the brain: development and use of a brain slice model. J Cell Biochem. 2006;97:217-25.

29. Vornicova O, Boyango I, Feld S, Naroditsky I, Kazarin O, Zohar Y, Tiram Y, Ilan N, Ben-Izhak O, Vlodavsky I, Bar-Sela G. The prognostic significance of heparanase expression in metastatic melanoma. Oncotarget. 2016;7:74678-85.

30. Kienast $Y$, von Baumgarten L, Fuhrmann M, Klinkert WE, Goldbrunner R, Herms J, Winkler F. Real-time imaging reveals the single steps of brain metastasis formation. Nat Med. 2010;16:116-22.

31. Saxena M, Christofori G. Rebuilding cancer metastasis in the mouse. Mol Oncol. 2013;7:283-96.

32. Simonsen TG, Gaustad JV, Rofstad EK. Intracranial tumor cell migration and the development of multiple brain metastases in malignant melanoma. Transl Oncol. 2016;9:211-8.

33. Cheng L, Lopez-Beltran A, Massari F, MacLennan GT, Montironi R. Molecular testing for BRAF mutations to inform melanoma treatment decisions: a move toward precision medicine. Mod Pathol. 2018;31:24-38.

34. Poynter JN, Elder JT, Fullen DR, Nair RP, Soengas MS, Johnson TM, Redman B, Thomas NE, Gruber SB. BRAF and NRAS mutations in melanoma and melanocytic nevi. Melanoma Res. 2006;16:267-73.

35. Greaves WO, Verma S, Patel KP, Davies MA, Barkoh BA, Galbincea JM, Yao H, Lazar AJ, Aldape KD, Medeiros LJ, Luthra R. Frequency and spectrum of BRAF mutations in a retrospective, single-institution study of 1112 cases of melanoma. J Mol Diagn. 2013;15:220-6.

36. Colombino M, Capone M, Lissia A, Cossu A, Rubino C, De Giorgi V, Massi D, Fonsatti E, Staibano S, Nappi O, et al. BRAF/NRAS mutation frequencies among primary tumors and metastases in patients with melanoma. J Clin Oncol. 2012:30:2522-9.

37. Bentley NJ, Eisen T, Goding CR. Melanocyte-specific expression of the human tyrosinase promoter: activation by the microphthalmia gene product and role of the initiator. Mol Cell Biol. 1994;14:7996-8006.

38. Dankort D, Curley DP, Cartlidge RA, Nelson B, Karnezis AN, Damsky WE Jr, You MJ, DePinho RA, McMahon M, Bosenberg M. Braf (V600E) cooperates with Pten loss to induce metastatic melanoma. Nat Genet. 2009:41:544-52.

39. Stambolic V, Suzuki A, de la Pompa JL, Brothers GM, Mirtsos C, Sasaki T, Ruland J, Penninger JM, Siderovski DP, Mak TW. Negative regulation of PKB/ Akt-dependent cell survival by the tumor suppressor PTEN. Cell. 1998;95:29-39.

40. Cho JH, Robinson JP, Arave RA, Burnett WJ, Kircher DA, Chen G, Davies MA, Grossmann AH, VanBrocklin MW, McMahon M, Holmen SL. AKT1 activation promotes development of melanoma metastases. Cell Rep. 2015;13:898-905.

41. Bucheit AD, Chen G, Siroy A, Tetzlaff M, Broaddus R, Milton D, Fox P, Bassett R, Hwu P, Gershenwald JE, et al. Complete loss of PTEN protein expression correlates with shorter time to brain metastasis and survival in stage IIIB/C melanoma patients with BRAFV600 mutations. Clin Cancer Res. 2014;20:5527-36.

42. Davies MA, Stemke-Hale K, Lin E, Tellez C, Deng W, Gopal YN, Woodman SE, Calderone TC, Ju Z, Lazar AJ, et al. Integrated molecular and clinical analysis of AKT activation in metastatic melanoma. Clin Cancer Res. 2009:15:7538-46.

43. Jakob JA, Bassett RL Jr, Ng CS, Curry JL, Joseph RW, Alvarado GC, Rohlfs ML, Richard J, Gershenwald JE, Kim KB, et al. NRAS mutation status is an independent prognostic factor in metastatic melanoma. Cancer. 2012;118:4014-23.

44. Sperduto PW, Jiang W, Brown PD, Braunstein S, Sneed P, Wattson DA, Shih HA, Bangdiwala A, Shanley R, Lockney NA, et al. The prognostic value of BRAF, C-KIT, and NRAS mutations in melanoma patients with brain metastases. Int J Radiat Oncol Biol Phys. 2017:98:1069-77.

45. Niessner H, Forschner A, Klumpp B, Honegger JB, Witte M, Bornemann A, Dummer R, Adam A, Bauer J, Tabatabai G, et al. Targeting hyperactivation of the AKT survival pathway to overcome therapy resistance of melanoma brain metastases. Cancer Med. 2013;2:76-85.

46. Chen G, Chakravarti N, Aardalen K, Lazar AJ, Tetzlaff MT, Wubbenhorst B, Kim SB, Kopetz S, Ledoux AA, Gopal YN, et al. Molecular profiling of patientmatched brain and extracranial melanoma metastases implicates the PI3K pathway as a therapeutic target. Clin Cancer Res. 2014;20:5537-46.

47. McFarland CD, Yaglom JA, Wojtkowiak JW, Scott JG, Morse DL, Sherman MY, Mirny LA. The damaging effect of passenger mutations on Cancer progression. Cancer Res. 2017;77:4763-72.

48. Bozic I, Antal T, Ohtsuki H, Carter H, Kim D, Chen S, Karchin R, Kinzler KW, Vogelstein B, Nowak MA. Accumulation of driver and passenger mutations during tumor progression. Proc Natl Acad Sci U S A. 2010;107:18545-50.

49. Capper D, Berghoff AS, Magerle M, Ihan A, Wohrer A, Hackl M, Pichler J Pusch S, Meyer J, Habel A. Immunohistochemical testing of BRAF V600E 
status in 1,120 tumor tissue samples of patients with brain metastases. Acta Neuropathol. 2012;123:223-et al.

50. Davies JE, Huang C, Proschel C, Noble M, Mayer-Proschel M, Davies SJ. Astrocytes derived from glial-restricted precursors promote spinal cord repair. J Biol. 2006:5:7.

51. Lessmann V, Gottmann K, Malcangio M. Neurotrophin secretion: current facts and future prospects. Prog Neurobiol. 2003;69:341-74.

52. Choi SS, Lee HJ, Lim I, Satoh J, Kim SU. Human astrocytes: secretome profiles of cytokines and chemokines. PLoS One. 2014;9:e92325.

53. Wilson BJ, Saab KR, Ma J, Schatton T, Putz P, Zhan Q, Murphy GF, Gasser M, Waaga-Gasser AM, Frank NY, Frank MH. ABCB5 maintains melanomainitiating cells through a proinflammatory cytokine signaling circuit. Cancer Res. 2014;74:4196-207.

54. Zhang L, Zhang S, Yao J, Lowery FJ, Zhang Q, Huang WC, Li P, Li M, Wang $X$, Zhang $C$, et al. Microenvironment-induced PTEN loss by exosomal microRNA primes brain metastasis outgrowth. Nature. 2015;527:100-4

55. Mu $P$, Han $Y C$, Betel D, Yao E, Squatrito $M$, Ogrodowski $P$, de Stanchina E, D'Andrea A, Sander C, Ventura A. Genetic dissection of the miR-17 92 cluster of microRNAs in Myc-induced B-cell lymphomas. Genes Dev. 2009;23:2806-11.

56. Park ES, Kim SJ, Kim SW, Yoon SL, Leem SH, Kim SB, Kim SM, Park YY, Cheong $\mathrm{JH}$, Woo HG, et al. Cross-species hybridization of microarrays for studying tumor transcriptome of brain metastasis. Proc Natl Acad Sci U S A. 2011;108:17456-61.

57. Lin Q, Balasubramanian K, Fan D, Kim SJ, Guo L, Wang H, Bar-Eli M, Aldape $\mathrm{KD}$, Fidler IJ. Reactive astrocytes protect melanoma cells from chemotherapy by sequestering intracellular calcium through gap junction communication channels. Neoplasia. 2010;12:748-54.

58. Jilaveanu LB, Parisi F, Barr ML, Zito CR, Cruz-Munoz W, Kerbel RS, Rimm DL, Bosenberg MW, Halaban R, Kluger Y, Kluger HM. PLEKHA5 as a biomarker and potential mediator of melanoma brain metastasis. Clin Cancer Res. 2015;21:2138-47.

59. Eisele SC, Gill CM, Shankar GM, Brastianos PK. PLEKHA5: a key to unlock the blood-brain barrier? Clin Cancer Res. 2015;21:1978-80.

60. Yamada K, Nomura N, Yamano A, Yamada Y, Wakamatsu N. Identification and characterization of splicing variants of PLEKHA5 (Plekha5) during brain development. Gene. 2012;492:270-5.

61. Xie TX, Huang FJ, Aldape KD, Kang SH, Liu M, Gershenwald JE, Xie K, Sawaya R, Huang S. Activation of stat3 in human melanoma promotes brain metastasis. Cancer Res. 2006;66:3188-96.

62. Patel JK, Didolkar MS, Pickren JW, Moore RH. Metastatic pattern of malignant melanoma. A study of 216 autopsy cases. Am J Surg. 1978; 135:807-10.

63. Santarelli R, Gonnella R, Di Giovenale G, Cuomo L, Capobianchi A, Granato M, Gentile G, Faggioni A, Cirone M. STAT3 activation by KSHV correlates with IL-10, IL-6 and IL-23 release and an autophagic block in dendritic cells. Sci Rep. 2014:4:4241.

64. Huang FJ, Steeg PS, Price JE, Chiu WT, Chou PC, Xie K, Sawaya R, Huang S. Molecular basis for the critical role of suppressor of cytokine signaling-1 in melanoma brain metastasis. Cancer Res. 2008;68:9634-42.

65. Lee I, Fox PS, Ferguson SD, Bassett R, Kong LY, Schacherer CW, Gershenwald JE, Grimm EA, Fuller GN, Heimberger AB. The expression of p-STAT3 in stage IV melanoma: risk of CNS metastasis and survival. Oncotarget. 2012;3:336-44.

66. Zhang C, Zhang F, Tsan R, Fidler IJ. Transforming growth factor-beta2 is a molecular determinant for site-specific melanoma metastasis in the brain. Cancer Res. 2009;69:828-35.

67. Kircher DA, Silvis MR, Cho JH, Holmen SL. Melanoma brain metastasis: mechanisms, models, and medicine. Int J Mol Sci. 2016;17(9):1468.

68. Cruz-Munoz W, Jaramillo ML, Man S, Xu P, Banville M, Collins C, Nantel A, Francia G, Morgan SS, Cranmer LD, et al. Roles for endothelin receptor $B$ and $B C L 2 A 1$ in spontaneous CNS metastasis of melanoma. Cancer Res. 2012;72:4909-19.

69. Muller A, Homey B, Soto H, Ge N, Catron D, Buchanan ME, McClanahan T, Murphy E, Yuan W, Wagner SN, et al. Involvement of chemokine receptors in breast cancer metastasis. Nature. 2001:410:50-6.

70. Klein A, Sagi-Assif O, Meshel T, Telerman A, Izraely S, Ben-Menachem S, Bayry J, Marzese DM, Ohe S, Hoon DSB, et al. CCR4 is a determinant of melanoma brain metastasis. Oncotarget. 2017:8:31079-91.

71. Ou B, Zhao J, Guan S, Feng H, Wangpu X, Zhu C, Zong Y, Ma J, Sun J, Shen $X$, et al. CCR4 promotes metastasis via ERK/NF-kappaB/MMP13 pathway and acts downstream of TNF-alpha in colorectal cancer. Oncotarget. 2016;7:47637-49.

72. Al-haidari AA, Syk I, Jirstrom K, Thorlacius H. CCR4 mediates CCL17 (TARC)induced migration of human colon cancer cells via RhoA/rho-kinase signaling. Int J Color Dis. 2013;28:1479-87.

73. Klein A, Schwartz H, Sagi-Assif O, Meshel T, Izraely S, Ben Menachem S, Bengaiev R, Ben-Shmuel A, Nahmias C, Couraud PO, et al. Astrocytes facilitate melanoma brain metastasis via secretion of IL-23. J Pathol. 2015;236:116-27.

74. Schwartz H, Blacher E, Amer M, Livneh N, Abramovitz L, Klein A, BenShushan D, Soffer S, Blazquez R, Barrantes-Freer A, et al. Incipient melanoma brain metastases instigate Astrogliosis and Neuroinflammation. Cancer Res. 2016;76:4359-71.

75. Sauka-Spengler T, Bronner-Fraser M. A gene regulatory network orchestrates neural crest formation. Nat Rev Mol Cell Biol. 2008;9:557-68.

76. Shakhova O, Zingg D, Schaefer SM, Hari L, Civenni G, Blunschi J, Claudinot S, Okoniewski M, Beermann F, Mihic-Probst D, et al. Sox10 promotes the formation and maintenance of giant congenital naevi and melanoma. Nat Cell Biol. 2012;14:882-90.

77. Bailey CM, Morrison JA, Kulesa PM. Melanoma revives an embryonic migration program to promote plasticity and invasion. Pigment Cell Melanoma Res. 2012;25:573-83.

78. Redmer T, Welte Y, Behrens D, Fichtner I, Przybilla D, Wruck W, Yaspo ML, Lehrach H, Schafer R, Regenbrecht CR. The nerve growth factor receptor CD271 is crucial to maintain tumorigenicity and stem-like properties of melanoma cells. PLoS One. 2014;9:e92596.

79. Marchetti D, Aucoin R, Blust J, Murry B, Greiter-Wilke A. p75 neurotrophin receptor functions as a survival receptor in brainmetastatic melanoma cells. J Cell Biochem. 2004;91:206-15.

80. Denkins Y, Reiland J, Roy M, Sinnappah-Kang ND, Galjour J, Murry BP, Blust $J$, Aucoin R, Marchetti D. Brain metastases in melanoma: roles of neurotrophins. Neuro-Oncology. 2004;6:154-65.

81. Shonukan O, Bagayogo I, McCrea P, Chao M, Hempstead B. Neurotrophininduced melanoma cell migration is mediated through the actin-bundling protein fascin. Oncogene. 2003;22:3616-23.

82. Menter DG, Herrmann JL, Marchetti D, Nicolson GL. Involvement of neurotrophins and growth factors in brain metastasis formation. Invasion Metastasis. 1994:14:372-84.

83. Marchetti D, McQuillan DJ, Spohn WC, Carson DD, Nicolson GL. Neurotrophin stimulation of human melanoma cell invasion: selected enhancement of heparanase activity and heparanase degradation of specific heparan sulfate subpopulations. Cancer Res. 1996;56:2856-63.

84. Gingis-Velitski S, Zetser A, Flugelman MY, Vlodavsky I, Ilan N. Heparanase induces endothelial cell migration via protein kinase B/Akt activation. J Biol Chem. 2004:279:23536-41.

85. Guo R, Fierro-Fine A, Goddard L, Russell M, Chen J, Liu CZ, Fung KM, Hassell LA. Increased expression of melanoma stem cell marker CD271 in metastatic melanoma to the brain. Int J Clin Exp Pathol. 2014;7:8947-51.

86. Boiko AD. Isolation of melanoma tumor-initiating cells from surgical tissues. Methods Mol Biol. 2013;961:253-9.

87. Boiko AD, Razorenova OV, van de Rijn M, Swetter SM, Johnson DL, Ly DP, Butler PD, Yang GP, Joshua B, Kaplan MJ, et al. Human melanoma-initiating cells express neural crest nerve growth factor receptor CD271. Nature. 2010;466:133-7.

88. Redmer T, Walz I, Klinger B, Khouja S, Welte Y, Schafer R, Regenbrecht C. The role of the cancer stem cell marker CD271 in DNA damage response and drug resistance of melanoma cells. Oncogenesis. 2017;6:e291.

89. Lu H, Liu S, Zhang G, Kwong LN, Zhu Y, Miller JP, Hu Y, Zhong W, Zeng J, Wu L, et al. Oncogenic BRAF-Mediated Melanoma Cell Invasion. Cell Rep. 2016;15:2012-24.

90. Arozarena I, Sanchez-Laorden B, Packer L, Hidalgo-Carcedo C, Hayward R, Viros A, Sahai E, Marais R. Oncogenic BRAF induces melanoma cell invasion by downregulating the CGMP-specific phosphodiesterase PDE5A. Cancer Cell. 2011;19:45-57.

91. Wu QF, Yang L, Li S, Wang Q, Yuan XB, Gao X, Bao L, Zhang X. Fibroblast growth factor 13 is a microtubule-stabilizing protein regulating neuronal polarization and migration. Cell. 2012;149:1549-64.

92. Sensi M, Catani M, Castellano G, Nicolini G, Alciato F, Tragni G, De Santis G, Bersani I, Avanzi G, Tomassetti A, et al. Human cutaneous melanomas lacking MITF and melanocyte differentiation antigens express a functional Axl receptor kinase. J Invest Dermatol. 2011;131:2448-57. 
93. Nygaard V, Prasmickaite L, Vasiliauskaite K, Clancy T, Hovig E. Melanoma brain colonization involves the emergence of a brain-adaptive phenotype. Oncoscience. 2014;1:82-94

94. Cheli Y, Bonnazi VF, Jacquel A, Allegra M, De Donatis GM, Bahadoran P, Bertolotto C, Ballotti R. CD271 is an imperfect marker for melanoma initiating cells. Oncotarget. 2014;5:5272-83.

95. Sandru A, Voinea S, Panaitescu E, Blidaru A. Survival rates of patients with metastatic malignant melanoma. J Med Life. 2014;7:572-6.

96. Gampa G, Vaidhyanathan S, Sarkaria JN, Elmquist WF. Drug delivery to melanoma brain metastases: can current challenges lead to new opportunities? Pharmacol Res. 2017;123:10-25.

97. Chang J, Atkinson H, A'Hern R, Lorentzos A, Gore ME. A phase II study of the sequential administration of dacarbazine and fotemustine in the treatment of cerebral metastases from malignant melanoma. Eur J Cancer. 1994;30A:2093-5.

98. Avril MF, Aamdal S, Grob JJ, Hauschild A, Mohr P, Bonerandi JJ, Weichenthal M, Neuber K, Bieber T, Gilde K, et al. Fotemustine compared with dacarbazine in patients with disseminated malignant melanoma: a phase III study. J Clin Oncol. 2004;22:1118-25.

99. Chiarion-Sileni V, Guida M, Ridolfi L, Romanini A, Del Bianco P, Pigozzo J, Brugnara S, Colucci G, Ridolfi R, De Salvo GL. Central nervous system failure in melanoma patients: results of a randomised, multicentre phase 3 study of temozolomideand dacarbazine- based regimens. Br J Cancer. 2011;104:1816-21.

100. Middleton MR, Grob JJ, Aaronson N, Fierlbeck G, Tilgen W, Seiter S, Gore M, Aamdal S, Cebon J, Coates A, et al. Randomized phase III study of temozolomide versus dacarbazine in the treatment of patients with advanced metastatic malignant melanoma. J Clin Oncol. 2000;18:158-66.

101. Obenauf AC, Massague J. Surviving at a distance: organ specific metastasis. Trends Cancer. 2015;1:76-91.

102. Vinay DS, Ryan EP, Pawelec G, Talib WH, Stagg J, Elkord E, Lichtor T, Decker WK, Whelan RL, Kumara HM, et al. Immune evasion in cancer: mechanistic basis and therapeutic strategies. Semin Cancer Biol. 2015;35(Suppl):S185-98.

103. Spranger S, Spaapen RM, Zha Y, Williams J, Meng Y, Ha TT, Gajewski TF. Upregulation of PD-L1, IDO, and T (regs) in the melanoma tumor microenvironment is driven by CD8(+) T cells. Sci Transl Med. 2013:5:200ra116.

104. Jacobs JF, Nierkens S, Figdor CG, de Vries IJ, Adema GJ. Regulatory T cells in melanoma: the final hurdle towards effective immunotherapy? Lancet Oncol. 2012;13:e32-42.

105. Freeman GJ, Long AJ, Iwai $Y$, Bourque $K$, Chernova T, Nishimura $H$, Fitz $L$, Malenkovich N, Okazaki T, Byrne MC, et al. Engagement of the PD-1 immunoinhibitory receptor by a novel B7 family member leads to negative regulation of lymphocyte activation. J Exp Med. 2000;192:1027-34.

106. Zhou J, Mahoney KM, Giobbie-Hurder A, Zhao F, Lee S, Liao X, Rodig S, Li J, Wu X, Butterfield LH, et al. Soluble PD-L1 as a biomarker in malignant melanoma treated with checkpoint blockade. Cancer Immunol Res. 2017;5:480-92.

107. Kaunitz GJ, Cottrell TR, Lilo M, Muthappan V, Esandrio J, Berry S, Xu H, Ogurtsova A, Anders RA, Fischer AH, et al. Melanoma subtypes demonstrate distinct PD-L1 expression profiles. Lab Investig. 2017;97:1063-71.

108. Robert C, Ribas A, Wolchok JD, Hodi FS, Hamid O, Kefford R, Weber JS, Joshua AM, Hwu WJ, Gangadhar TC, et al. Anti-programmed-deathreceptor-1 treatment with pembrolizumab in ipilimumab-refractory advanced melanoma: a randomised dose-comparison cohort of a phase 1 trial. Lancet. 2014;384:1109-17.

109. Topalian SL, Sznol M, McDermott DF, Kluger HM, Carvajal RD, Sharfman WH, Brahmer JR, Lawrence DP, Atkins MB, Powderly JD, et al. Survival, durable tumor remission, and long-term safety in patients with advanced melanoma receiving nivolumab. J Clin Oncol. 2014;32:1020-30.

110. Gadiot J, Hooijkaas Al, Kaiser AD, van Tinteren $H$, van Boven $H$, Blank $C$. Overall survival and PD-L1 expression in metastasized malignant melanoma. Cancer. 2011;117:2192-201.

111. Goldberg SB, Gettinger SN, Mahajan A, Chiang AC, Herbst RS, Sznol M, Tsiouris AJ, Cohen J, Vortmeyer A, Jilaveanu L, et al. Pembrolizumab for patients with melanoma or non-small-cell lung cancer and untreated brain metastases: early analysis of a non-randomised, open-label, phase 2 trial. Lancet Oncol. 2016;17:976-83.

112. Gangadhar TC, Vonderheide RH. Mitigating the toxic effects of anticancer immunotherapy. Nat Rev Clin Oncol. 2014;11:91-9.

113. Hodi FS, O'Day SJ, McDermott DF, Weber RW, Sosman JA, Haanen JB, Gonzalez R, Robert C, Schadendorf D, Hassel JC, et al. Improved survival with ipilimumab in patients with metastatic melanoma. N Engl J Med. 2010;363:711-23.

114. Stummer W. Mechanisms of tumor-related brain edema. Neurosurg Focus. 2007;22:E8.
115. Margolin K, Ernstoff MS, Hamid O, Lawrence D, McDermott D, Puzanov 1. Wolchok JD, Clark JI, Sznol M, Logan TF, et al. Ipilimumab in patients with melanoma and brain metastases: an open-label, phase 2 trial. Lancet Oncol. 2012;13:459-65.

116. Carter T, Shaw H, Cohn-Brown D, Chester K, Mulholland P. Ipilimumab and bevacizumab in glioblastoma. Clin Oncol (R Coll Radiol). 2016;28:622-6.

117. Cohen JV, Kluger HM. Systemic immunotherapy for the treatment of brain metastases. Front Oncol. 2016;6:49.

118. Westphal D, Glitza Oliva IC, Niessner H. Molecular insights into melanoma brain metastases. Cancer. 2017;123:2163-75.

119. Chukwueke U, Batchelor T, Brastianos P. Management of Brain Metastases in patients with melanoma. J Oncol Pract. 2016;12:536-42.

120. Tawbi HA-H, Forsyth PAJ, Algazi AP, Hamid O, Hodi FS, Moschos SJ, Khushalani NI, Gonzalez R, Lao CD, Postow MA, et al. Efficacy and safety of nivolumab (NIVO) plus ipilimumab (IPI) in patients with melanoma (MEL) metastatic to the brain: results of the phase II study CheckMate 204. J Clin Oncol. 2017:35:9507.

121. Silk AW, Bassetti MF, West BT, Tsien Cl, Lao CD. Ipilimumab and radiation therapy for melanoma brain metastases. Cancer Med. 2013;2:899-906.

122. Long GV, Atkinson V, Lo S, Sandhu S, Guminski AD, Brown MP, Wilmott JS, Edwards J, Gonzalez M, Scolyer RA, et al. Combination nivolumab and ipilimumab or nivolumab alone in melanoma brain metastases: a multicentre randomised phase 2 study. Lancet Oncol. 2018;19:672-81.

123. Gopalakrishnan V, Spencer CN, Nezi L, Reuben A, Andrews MC, Karpinets TV, Prieto PA, Vicente D, Hoffman K, Wei SC, et al. Gut microbiome modulates response to anti-PD-1 immunotherapy in melanoma patients. Science. 2018;359:97-103.

124. Pukrop T, Dehghani F, Chuang HN, Lohaus R, Bayanga K, Heermann S, Regen T, Van Rossum D, Klemm F, Schulz M, et al. Microglia promote colonization of brain tissue by breast cancer cells in a Wnt-dependent way. Glia. 2010;58:1477-89.

125. Davies H, Bignell GR, Cox C, Stephens P, Edkins S, Clegg S, Teague J, Woffendin H, Garnett MJ, Bottomley W, et al. Mutations of the BRAF gene in human cancer. Nature. 2002:417:949-54.

126. Sosman JA, Kim KB, Schuchter L, Gonzalez R, Pavlick AC, Weber JS, McArthur GA, Hutson TE, Moschos SJ, Flaherty KT, et al. Survival in BRAF V600-mutant advanced melanoma treated with vemurafenib. N Engl J Med. 2012:366:707-14.

127. Mittapalli RK, Vaidhyanathan S, Sane R, Elmquist WF. Impact of Pglycoprotein $(A B C B 1)$ and breast cancer resistance protein $(A B C G 2)$ on the brain distribution of a novel BRAF inhibitor: vemurafenib (PLX4032). J Pharmacol Exp Ther. 2012;342:33-40.

128. Dummer R, Goldinger SM, Turtschi CP, Eggmann NB, Michielin O, Mitchell $L$, Veronese L, Hilfiker PR, Felderer L, Rinderknecht JD. Vemurafenib in patients with BRAF (V600) mutation-positive melanoma with symptomatic brain metastases: final results of an open-label pilot study. Eur J Cancer. 2014;50:611-21.

129. McArthur GA, Maio M, Arance A, Nathan P, Blank C, Avril MF, Garbe C, Hauschild A, Schadendorf D, Hamid O, et al. Vemurafenib in metastatic melanoma patients with brain metastases: an open-label, single-arm, phase 2, multicentre study. Ann Oncol. 2017;28:634-41.

130. Long GV, Trefzer U, Davies MA, Kefford RF, Ascierto PA, Chapman PB, Puzanov I, Hauschild A, Robert C, Algazi A, et al. Dabrafenib in patients with Val600Glu or Val600Lys BRAF-mutant melanoma metastatic to the brain (BREAK-MB): a multicentre, open-label, phase 2 trial. Lancet Oncol. 2012;13:1087-95.

131. Mathieu D, Kondziolka D, Cooper PB, Flickinger JC, Niranjan A, Agarwala S, Kirkwood J, Lunsford LD. Gamma knife radiosurgery for malignant melanoma brain metastases. Clin Neurosurg. 2007;54:241-7.

132. Yamamoto M, Serizawa T, Shuto T, Akabane A, Higuchi $Y$, Kawagishi J, Yamanaka K, Sato Y, Jokura H, Yomo S, et al. Stereotactic radiosurgery for patients with multiple brain metastases (JLGK0901): a multi-institutional prospective observational study. Lancet Oncol. 2014;15:387-95.

133. Mohammadi AM, Recinos PF, Barnett GH, Weil RJ, Vogelbaum MA, Chao ST, Suh JH, Marko NF, Elson P, Neyman G, Angelov L. Role of gamma knife surgery in patients with 5 or more brain metastases. J Neurosurg. 2012;117(Suppl):5-12

134. McTyre E, Scott J, Chinnaiyan P. Whole brain radiotherapy for brain metastasis. Surg Neurol Int. 2013;4:S236-44.

135. Valk PE, Dillon WP. Radiation injury of the brain. AJNR Am J Neuroradiol. 1991;12:45-62.

136. Mahajan A, Ahmed S, McAleer MF, Weinberg JS, Li J, Brown P, Settle S, Prabhu SS, Lang FF, Levine $\mathrm{N}$, et al. Post-operative stereotactic radiosurgery 
versus observation for completely resected brain metastases: a singleCentre, randomised, controlled, phase 3 trial. Lancet Oncol. 2017;18:1040-8.

137. Soliman H, Das S, Larson DA, Sahgal A. Stereotactic radiosurgery (SRS) in the modern management of patients with brain metastases. Oncotarget. 2016;7:12318-30.

138. Anderson ES, Postow MA, Wolchok JD, Young RJ, Ballangrud A, Chan TA Yamada Y, Beal K. Melanoma brain metastases treated with stereotactic radiosurgery and concurrent pembrolizumab display marked regression; efficacy and safety of combined treatment. J Immunother Cancer. 2017;5:76.

139. Hauschild A, Grob JJ, Demidov LV, Jouary T, Gutzmer R, Millward M, Rutkowski P, Blank CU, Miller WH Jr, Kaempgen E, et al. Dabrafenib in BRAF-mutated metastatic melanoma: a multicentre, open-label, phase 3 randomised controlled trial. Lancet. 2012;380:358-65.

140. Chapman PB, Hauschild A, Robert C, Haanen JB, Ascierto P, Larkin J, Dummer R, Garbe C, Testori A, Maio M, et al. Improved survival with vemurafenib in melanoma with BRAF V600E mutation. N Engl J Med. 2011;364:2507-16

141. Chapman PB. Mechanisms of resistance to RAF inhibition in melanomas harboring a BRAF mutation. Am Soc Clin Oncol Educ Book. 2013;33:e80-2.

142. Nazarian R, Shi H, Wang Q, Kong X, Koya RC, Lee H, Chen Z, Lee MK, Attar $\mathrm{N}$, Sazegar H, et al. Melanomas acquire resistance to B-RAF(V600E) inhibition by RTK or N-RAS upregulation. Nature. 2010;468:973-7.

143. Sun C, Wang L, Huang S, Heynen GJ, Prahallad A, Robert C, Haanen J, Blank C, Wesseling J, Willems SM, et al. Reversible and adaptive resistance to BRAF (V600E) inhibition in melanoma. Nature. 2014;508:118-22.

144. Spagnolo F, Ghiorzo P, Orgiano L, Pastorino L, Picasso V, Tornari E, Ottaviano V, Queirolo P. BRAF-mutant melanoma: treatment approaches, resistance mechanisms, and diagnostic strategies. Onco Targets Ther. 2015;8:157-68.

145. Flaherty KT, Robert C, Hersey P, Nathan P, Garbe C, Milhem M, Demidov LV, Hassel JC, Rutkowski P, Mohr P, et al. Improved survival with MEK inhibition in BRAF-mutated melanoma. N Engl J Med. 2012;367:107-14.

146. Johnson DB, Flaherty KT, Weber JS, Infante JR, Kim KB, Kefford RF, Hamid O, Schuchter L, Cebon J, Sharfman WH, et al. Combined BRAF (Dabrafenib) and MEK inhibition (Trametinib) in patients with BRAFV600-mutant melanoma experiencing progression with single-agent BRAF inhibitor. J Clin Oncol. 2014:32:3697-704

147. Long GV, Fung C, Menzies AM, Pupo GM, Carlino MS, Hyman J, Shahheydari $\mathrm{H}$, Tembe $\mathrm{V}$, Thompson JF, Saw RP, et al. Increased MAPK reactivation in early resistance to dabrafenib/trametinib combination therapy of BRAFmutant metastatic melanoma. Nat Commun. 2014:5:5694.

148. Corcoran RB, Dias-Santagata D, Bergethon K, lafrate AJ, Settleman J, Engelman JA. BRAF gene amplification can promote acquired resistance to MEK inhibitors in cancer cells harboring the BRAF V600E mutation. Sci Signal. 2010;3:ra84.

149. Imafuku K, Yoshino K, Yamaguchi K, Tsuboi S, Ohara K, Hata H. Sudden onset of brain metastasis despite the use of Vemurafenib for another metastatic lesion in malignant melanoma patients. Case Rep Oncol. 2017;10:290-5.

150. Haueis SA, Kranzlin P, Mangana J, Cheng PF, Urosevic-Maiwald M, Braun RP, Levesque MP, Dummer R, Goldinger SM. Does the distribution pattern of brain metastases during BRAF inhibitor therapy reflect phenotype switching? Melanoma Res. 2017;27:231-7.

151. Kim M, Koh YJ, Kim KE, Koh BI, Nam DH, Alitalo K, Kim I, Koh GY. CXCR4 signaling regulates metastasis of chemoresistant melanoma cells by a lymphatic metastatic niche. Cancer Res. 2010;70:10411-21.

152. Monzani E, Facchetti F, Galmozzi E, Corsini E, Benetti A, Cavazzin C, Gritti A, Piccinini A, Porro D, Santinami M, et al. Melanoma contains CD133 and ABCG2 positive cells with enhanced tumourigenic potential. Eur J Cancer. 2007;43:935-46.

153. Bao S, Wu Q, McLendon RE, Hao Y, Shi Q, Hjelmeland AB, Dewhirst MW Bigner DD, Rich JN. Glioma stem cells promote radioresistance by preferential activation of the DNA damage response. Nature. 2006;444:756-60.

154. Woditschka S, Evans L, Duchnowska R, Reed LT, Palmieri D, Qian Y, Badve S, Sledge G, Gril B, Aladjem MI, et al. DNA Double-Strand Break Repair Genes and Oxidative Damage in Brain Metastasis of Breast Cancer. J Natl Cancer Inst. 2014;106:dju145.

155. Li HF, Kim JS, Waldman T. Radiation-induced Akt activation modulates radioresistance in human glioblastoma cells. Radiat Oncol. 2009:4:43.

156. Kauffmann A, Rosselli F, Lazar V, Winnepenninckx V, Mansuet-Lupo A Dessen P, van den Oord JJ, Spatz A, Sarasin A. High expression of DNA repair pathways is associated with metastasis in melanoma patients. Oncogene. 2008;27:565-73.
157. Lehraiki A, Cerezo M, Rouaud F, Abbe P, Allegra M, Kluza J, Marchetti P,

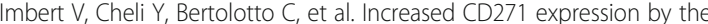
NF-kB pathway promotes melanoma cell survival and drives acquired resistance to BRAF inhibitor vemurafenib. Cell Discov. 2015:1:15030.

158. Zubrilov I, Sagi-Assif O, Izraely S, Meshel T, Ben-Menahem S, Ginat R, Pasmanik-Chor M, Nahmias C, Couraud PO, Hoon DS, Witz IP. Vemurafenib resistance selects for highly malignant brain and lung-metastasizing melanoma cells. Cancer Lett. 2015;361:86-96.

159. Seifert H, Hirata E, Gore M, Khabra K, Messiou C, Larkin J, Sahai E. Extrinsic factors can mediate resistance to BRAF inhibition in central nervous system melanoma metastases. Pigment Cell Melanoma Res. 2016:29:92-100.

160. Rappa G, Fodstad O, Lorico A. The stem cell-associated antigen CD133 (Prominin-1) is a molecular therapeutic target for metastatic melanoma. Stem Cells. 2008;26:3008-17.

161. Ngo M, Han A, Lakatos A, Sahoo D, Hachey SJ, Weiskopf K, Beck AH, Weissman IL, Boiko AD. Antibody therapy targeting CD47 and CD271 effectively suppresses melanoma metastasis in patient-derived xenografts. Cell Rep. 2016;16:1701-16.

162. Schatton T, Murphy GF, Frank NY, Yamaura K, Waaga-Gasser AM, Gasser M, Zhan Q, Jordan S, Duncan LM, Weishaupt C, et al. Identification of cells initiating human melanomas. Nature. 2008;451:345-9.
Ready to submit your research? Choose BMC and benefit from:

- fast, convenient online submission

- thorough peer review by experienced researchers in your field

- rapid publication on acceptance

- support for research data, including large and complex data types

- gold Open Access which fosters wider collaboration and increased citations

- maximum visibility for your research: over $100 \mathrm{M}$ website views per year

At $\mathrm{BMC}$, research is always in progress.

Learn more biomedcentral.com/submissions 